\title{
Anaphylactic and nonanaphylactic reactions to SARS-CoV-2 vaccines: a systematic review and meta-analysis
}

\author{
Saad Alhumaid ${ }^{1 *}$ (D), Abbas Al Mutair ${ }^{2,3,4}\left(\mathbb{0}\right.$, Zainab Al Alawi ${ }^{5}$, Ali A. Rabaan ${ }^{6,7}$, Raghavendra Tirupathi ${ }^{8,9}$, \\ Mohammed A. Alomari ${ }^{10}$, Aqeel S. Alshakhes ${ }^{11}$, Abeer M. Alshawi ${ }^{12}$, Gasmelseed Y. Ahmed ${ }^{2}$, \\ Hassan M. Almusabeh" ${ }^{1}$, Tariq T. Alghareeb ${ }^{1}$, Abdulaziz A. Alghuwainem ${ }^{13}$, Zainab A. Alsulaiman ${ }^{14}$, \\ Mohammed A. Alabdulmuhsin ${ }^{15}$, Emad A. AlBuwaidi ${ }^{16}$, Amjad K. Bu Dukhi ${ }^{17}$, Hani N. Mufti 18,19,20, \\ Manaf Al-Qahtani ${ }^{21,22}$, Kuldeep Dhama ${ }^{23}$, Jaffar A. Al-Tawfiq ${ }^{24,25,26}$ and Awad Al-Omari ${ }^{27,28}$
}

\begin{abstract}
Background: Currently there is no systematic review and meta-analysis of the global incidence rates of anaphylactic and nonanaphylactic reactions to SARS-CoV-2 vaccines in the general adult population.

Objectives: To estimate the incidence rates of anaphylactic and nonanaphylactic reactions after COVID-19 vaccines and describe the demographic and clinical characteristics, triggers, presenting signs and symptoms, treatment and clinical course of confirmed cases.

Design: A systematic review and meta-analysis. Preferred Reporting Items for Systematic Reviews and Meta-Analyses [PRISMA] statement was followed.

Methods: Electronic databases (Proquest, Medline, Embase, Pubmed, CINAHL, Wiley online library, and Nature) were searched from 1 December 2020 to 31 May 2021 in the English language using the following keywords alone or in combination: anaphylaxis, non-anaphylaxis, anaphylactic reaction, nonanaphylactic reaction, anaphylacticl anaphylactoid shock, hypersensitivity, allergy reaction, allergic reaction, immunology reaction, immunologic reaction, angioedema, loss of consciousness, generalized erythema, urticaria, urticarial rash, cyanosis, grunting, stridor, tachypnoea, wheezing, tachycardia, abdominal pain, diarrhea, nausea, vomiting and tryptase. We included studies in adults of all ages in all healthcare settings. Effect sizes of prevalence were pooled with 95\% confidence intervals (Cls). To minimize heterogeneity, we performed sub-group analyses.
\end{abstract}

Results: Of the 1,734 papers that were identified, 26 articles were included in the systematic review ( 8 case report, 5 cohort, 4 case series, 2 randomized controlled trial and 1 randomized cross-sectional studies) and 14 articles ( 1 cohort, 2 case series, 1 randomized controlled trial and 1 randomized cross-sectional studies) were included in meta-analysis. Studies involving 26,337,421 vaccine recipients [Pfizer-BioNTech $(n=14,505,399)$ and Moderna $(n=11,831,488)$ ] were analyzed. The overall pooled prevalence estimate of anaphylaxis to both vaccines was $5.0(95 \% \mathrm{Cl} 2.9$ to 7.2 , $P^{2}=81 \%, p=<0.0001$ ), while the overall pooled prevalence estimate of nonanaphylactic reactions to both vaccines

*Correspondence: saalhumaid@moh.gov.sa

${ }^{1}$ Administration of Pharmaceutical Care, Al-Ahsa Health Cluster, Ministry of Health, Rashdiah Street, P. O. Box 12944, Al-Ahsa 31982, Saudi Arabia

Full list of author information is available at the end of the article permits use, sharing, adaptation, distribution and reproduction in any medium or format, as long as you give appropriate credit to the original author(s) and the source, provide a link to the Creative Commons licence, and indicate if changes were made. The images or other third party material in this article are included in the article's Creative Commons licence, unless indicated otherwise in a credit line to the material. If material is not included in the article's Creative Commons licence and your intended use is not permitted by statutory regulation or exceeds the permitted use, you will need to obtain permission directly from the copyright holder. To view a copy of this licence, visit http://creativecommons.org/licenses/by/4.0/. The Creative Commons Public Domain Dedication waiver (http:// creativecommons.org/publicdomain/zero/1.0/) applies to the data made available in this article, unless otherwise stated in a credit line to the data. 
was $53.9\left(95 \% \mathrm{Cl} 0.0\right.$ to $\left.116.1, P^{2}=99 \%, p=<0.0001\right)$. Vaccination with Pfizer-BioNTech resulted in higher anaphylactic reactions compared to Moderna $\left(8.0,95 \% \mathrm{Cl} 0.0\right.$ to $11.3, P^{2}=85 \%$ versus $2.8,95 \% \mathrm{Cl} 0.0$ to $\left.5.7, P^{2}=59 \%\right)$. However, lower incidence of nonanaphylactic reactions was associated with Pfizer-BioNTech compared to Moderna (43.9, 95\% $\mathrm{Cl} 0.0$ to $131.9, P^{2}=99 \%$ versus $63.8,95 \% \mathrm{Cl} 0.0$ to $151.8, I^{2}=98 \%$ ). The funnel plots for possible publication bias for the pooled effect sizes to determine the incidence of anaphylaxis and nonanaphylactic reactions associated with mRNA COVID-19 immunization based on mRNA vaccine type appeared asymmetrical on visual inspection, and Egger's tests confirmed asymmetry by producing $p$ values $<0.05$. Across the included studies, the most commonly identified risk factors for anaphylactic and nonanaphylactic reactions to SARS-CoV-2 vaccines were female sex and personal history of atopy. The key triggers to anaphylactic and nonanaphylactic reactions identified in these studies included foods, medications, stinging insects or jellyfish, contrast media, cosmetics and detergents, household products, and latex. Previous history of anaphylaxis; and comorbidities such as asthma, allergic rhinitis, atopic and contact eczema/ dermatitis and psoriasis and cholinergic urticaria were also found to be important.

Conclusion: The prevalence of COVID-19 mRNA vaccine-associated anaphylaxis is very low; and nonanaphylactic reactions occur at higher rate, however, cutaneous reactions are largely self-limited. Both anaphylactic and nonanaphylactic reactions should not discourage vaccination.

Keywords: Allergic, COVID-19, Immunologic, Incidence, Reactions, SARS-Cov-2, Systematic review, Vaccines

\section{Background}

Globally, as of 28 May 2021, there have been $168,040,871$ confirmed cases of coronavirus disease 2019 (COVID-19), including 3,494,758 deaths, reported to the World Health Organization [1]. Immunization is an important strategy to halt COVID-19 pandemic. Two COVID-19 vaccines were granted emergency use authorization [EUA] by the United States Food and Drug Administration: the Pfizer-BioNTech COVID19 vaccine and the Moderna COVID-19 vaccine [2, 3]. Other vaccines had also been used or authorized in multiple parts of the world. Vaccination hesitancy is an important obstacle to achieve herd immunity [4-6]. One of the main reasons for vaccine hesitancy is the concerns about vaccine safety, adverse effects, or toxicity.

Adverse reactions to vaccines are commonly reported, but most are not immunologically mediated. Nonimmunologically mediated reactions are typically related to the pharmacology of the vaccine and consist of toxic reactions, side effects, and medication interactions [7]. Immunologically mediated reactions include IgEmediated and T-cell mediated reactions as well as other immunologic mechanisms that occur as a result of allergen exposure. These responses, particularly severe anaphylaxis, rarely occur [8, 9]. Symptoms can begin within minutes of exposure to the allergen [generally within $30 \mathrm{~min}$ and less commonly within several hours]; and range from urticaria, swelling, and gastrointestinal upset, to respiratory distress and cardiovascular collapse associated with severe anaphylaxis [9]. Delayed reactions typically occur hours to days after exposure to the antigen trigger, and most typically manifest as a cutaneous reaction [10].
Maintaining public confidence to minimize vaccine hesitancy is crucial as disease outbreaks among the unvaccinated population are likely to occur when herd immunity is compromised. We aimed to estimate the incidence rates of anaphylactic and nonanaphylactic reactions after mRNA COVID-19 vaccines (Pfizer/ BioNTech and Moderna) and describe the demographic and clinical characteristics, triggers, presenting signs and symptoms, treatment and clinical course of confirmed cases. We primarily focused this assessment on the Pfizer/BioNTech and Moderna mRNA vaccines given that reports of anaphylactic and nonanaphylactic reactions from adenovirus vaccines beyond clinical trials were limited.

\section{Methods \\ Design}

We followed the Preferred Reporting Items for Systematic Reviews and Meta-Analyses guidelines [PRISMA] in conducting this systematic review and meta-analysis [11]. The following electronic databases were searched: PROQUEST, MEDLINE, EMBASE, PUBMED, CINAHL, WILEY ONLINE LIBRARY, and NATURE with Full Text. We used the following keywords: anaphylaxis OR non-anaphylaxis OR anaphylactic reaction OR nonanaphylactic reaction OR anaphylactic/anaphylactoid shock OR hypersensitivity OR allergy reaction OR allergic reaction OR immunology reaction OR immunologic reaction AND angioedema OR loss of consciousness OR generalized erythema OR urticaria OR urticarial rash OR cyanosis OR grunting OR stridor OR tachypnoea OR wheezing OR tachycardia OR abdominal pain OR diarrhea OR nausea OR vomiting OR tryptase. The search was limited to papers 
published in English between 1 December 2020 and 31 May 2021. Based on the title and abstract of each selected article, we selected those discussing and reporting rates of anaphylactic and nonanaphylactic reactions to mRNA SARS-CoV-2 vaccines. We also utilized backward snowballing to increase the yield of potentially relevant articles.

\section{Inclusion and exclusion criteria}

We retained randomized controlled trials, cohort studies, case reports and case series and excluded other studies. We excluded studies that did not report data on anaphylactic and nonanaphylactic reactions to SARS-CoV-2 mRNA vaccines; or studies that never stated details on identified cases with anaphylactic and nonanaphylactic reactions. We evaluated studies that included all adults as our population of interest who received 1 or more doses of mRNA COVID-19 vaccines and reported evidence on anaphylactic and nonanaphylactic reactions during the period from December 1, 2020 through May 31, 2021.

\section{Data extraction}

Six authors (S.A., A.A., A.R., R.T., M.A.A., and Z.A.) critically reviewed all of the studies retrieved and selected those judged to be the most relevant. The abstracts of all citations were examined thoroughly. Data were extracted from the relevant research studies using key headings, which are noted in Tables 1 and 2, simplifying analysis, and review of the literature. Articles were categorized as randomized controlled trial, case report, case series or cohort studies. Studies were also categorized as a national or international online survey as we sought to describe reports of anaphylactic and nonanaphylactic reactions after mRNA COVID-19 vaccination made to the United States' Vaccine Adverse Event Reporting System (US-VAERS) and Canadian Ontario's vaccine safety surveillance system; or categorized as self-reported by vaccine recipients, mostly by healthcare workers, via an online questionnaire conducted to compare the safety of available mRNA COVID-19 vaccines.

The following data were extracted from selected studies: authors; publication year; study location; study design and setting; age; proportion of male patients; past history of allergies or allergic reactions and/or anaphylaxis; vaccine brand and dose [if 1st dose, 2nd dose or both]; time from vaccination to anaphylactic or nonanaphylactic reaction onset; signs and symptoms; anaphylaxis level of severity if occurred; treatment setting and therapy received for reaction; if epinephrine was received; treatment outcome; if skin test was performed and test result; assessment of included study risk of bias (tool used; finding) and; remarks on notable findings.

\section{Quality assessment}

The quality assessment of the studies was undertaken mainly based on the Newcastle-Ottawa Scale [NOS] to assess the quality of the selected studies [12]. This assessment scale has two different tools for evaluating case-control and cohort studies. Each tool measures quality in the three parameters of selection, comparability, and exposure/outcome, and allocates a maximum of 4,2 , and 3 points, respectively. Highquality studies are scored greater than 7 on this scale, and moderate-quality studies, between 5 and 7. Revised Cochrane risk of bias tool ( $R o B$ 2.0) was used to assess the risk of bias in randomized controlled studies [13]. Quality assessment was performed by five authors (H.M.A., A.S.A., T.T.A., G.A., and A.M.A.) independently, with any disagreement to be resolved by consensus.

\section{Data analysis}

The primary outcome of interest was to determine the incidence rates of anaphylactic and nonanaphylactic reactions induced after the administration of mRNA COVID-19 vaccines [namely Pfizer-BioNTech and Moderna]. Secondary outcome was to analyze identified evidence describing the demographic and clinical characteristics, triggers, presenting signs and symptoms, treatment and clinical course of confirmed cases with anaphylactic and nonanaphylactic reactions induced by those two mRNA vaccines. Taking a conservative approach, a random effects meta-analysis with the Hunter-Schmidt model was used [14], which produces wider confidence intervals [CIs] than a fixed effect model. Results were illustrated using forest plots. Statistical heterogeneity was evaluated using the Cochran's chisquare $\left(\chi^{2}\right)$ and the $I^{2}$ statistic [15]. An $I^{2}$ value of $>50 \%$ is suggestive of significant heterogeneity [16]. To detect the source of heterogeneity, subgroup analysis was performed based on vaccine brand administered [Pfizer-BioNTech or Moderna]. Publication bias was evaluated using funnel plots and the Egger's correlation test, with $\mathrm{p}<0.05$ indicating statistical significance [17]. All analyses were done using $R$ version 4.1 .0 with the packages metafor and meta.

\section{Results \\ Study characteristics and quality}

A total of 1,734 publications were identified (Fig. 1). After scanning titles and abstracts, we discarded 609 duplicate articles. Another 264 irrelevant articles were excluded based on the titles and abstracts. The full texts of the 416 remaining articles were reviewed, and 390 irrelevant articles were excluded. As a result, we identified 26 studies that met our inclusion criteria [18-41]. The 


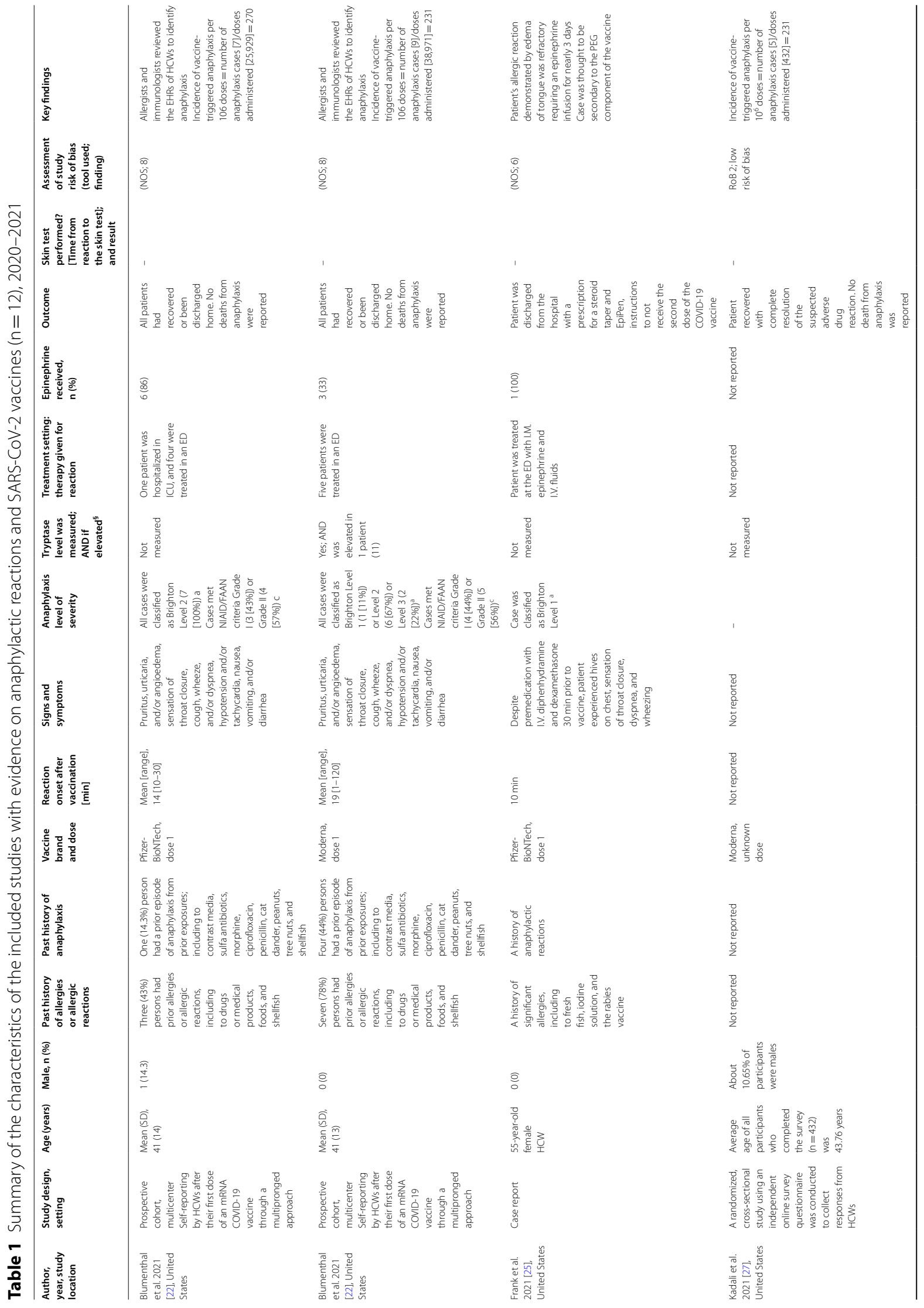




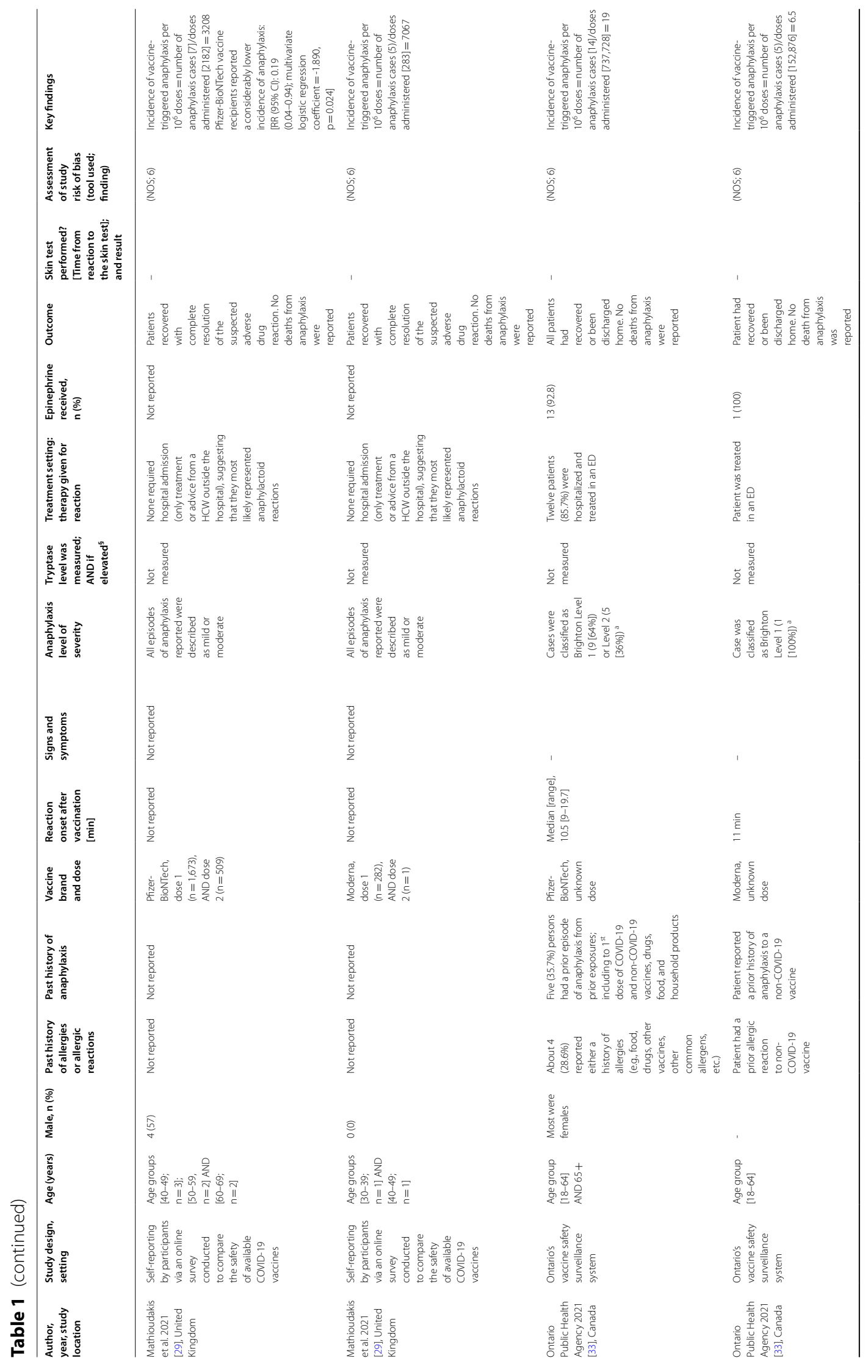




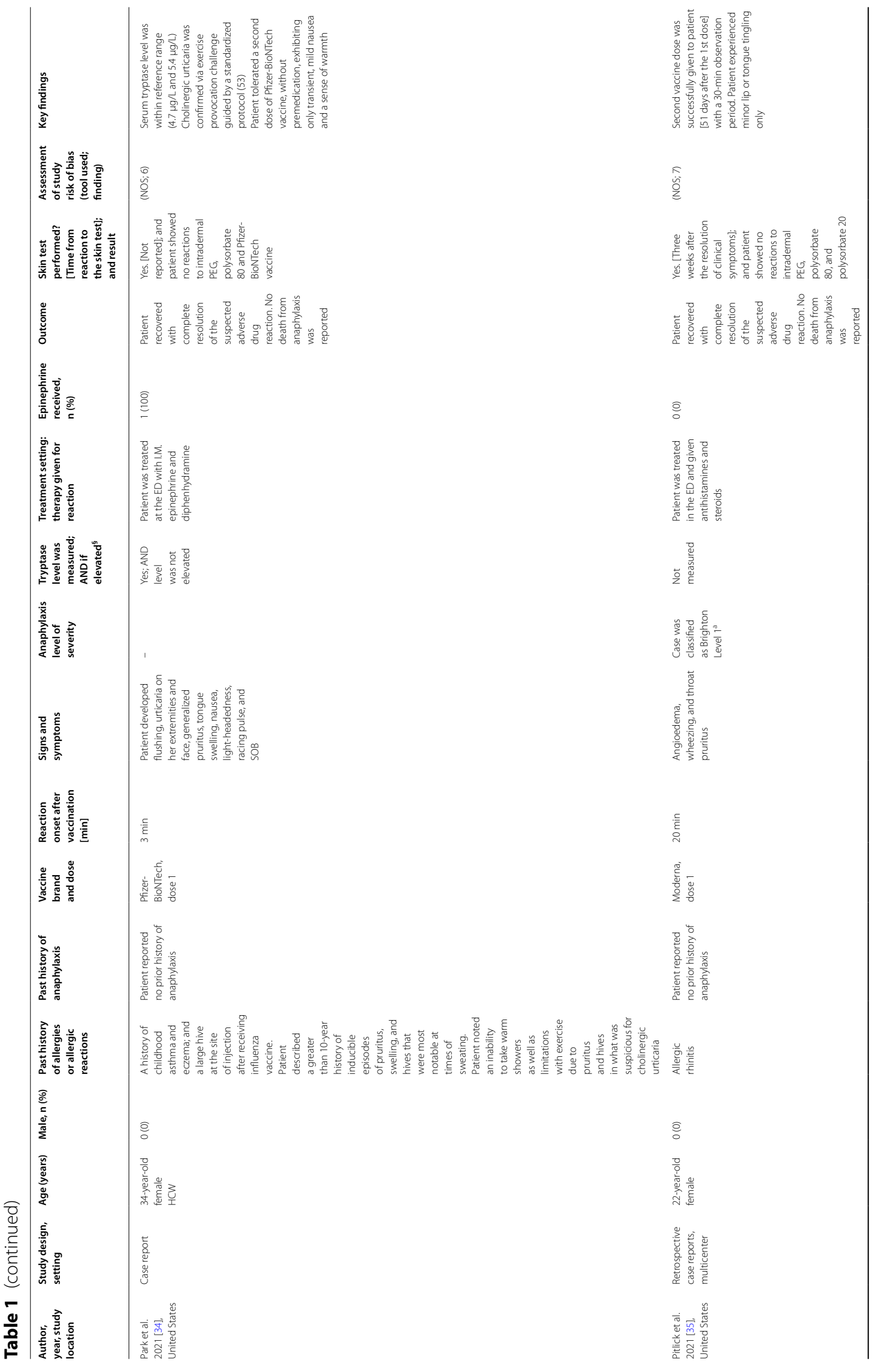




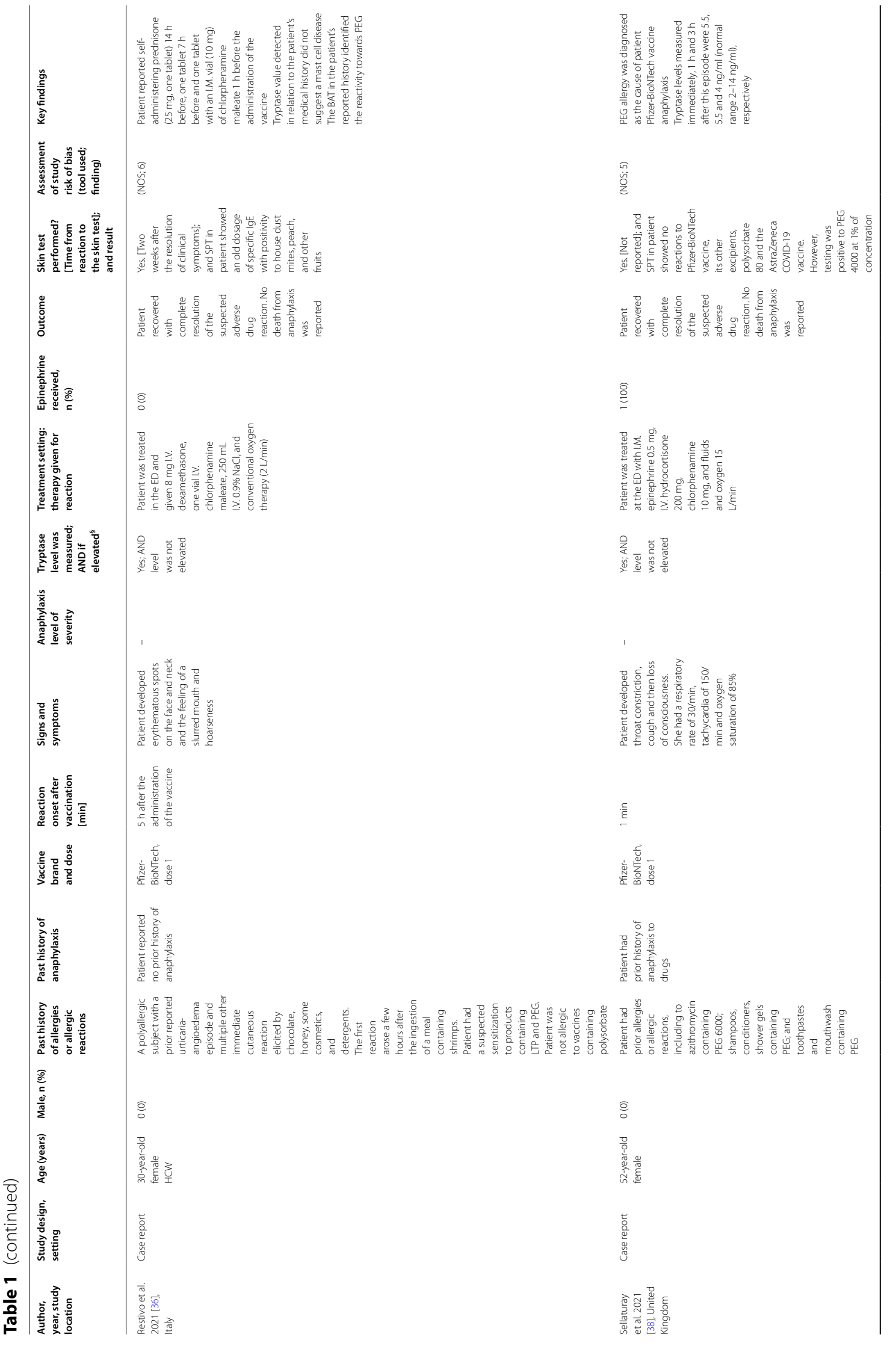




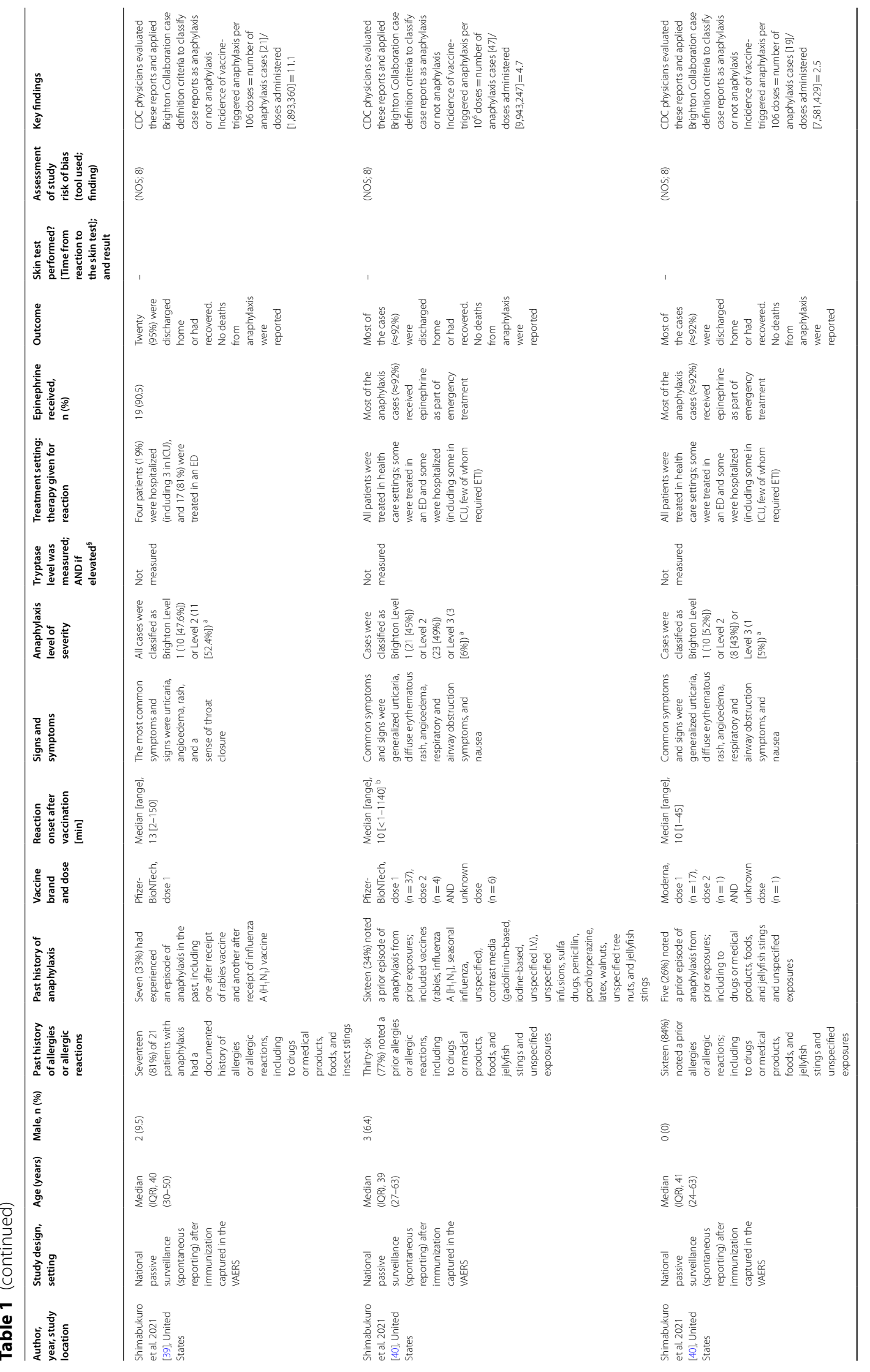




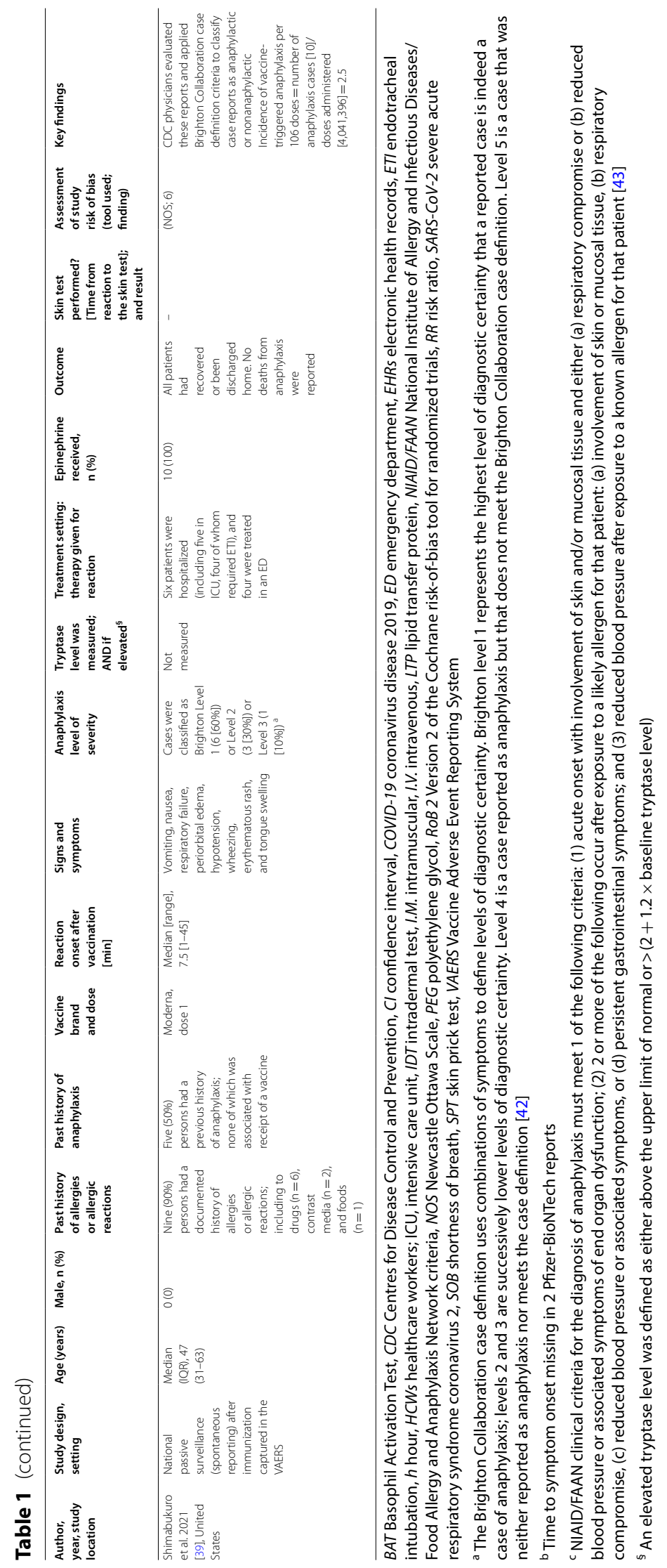




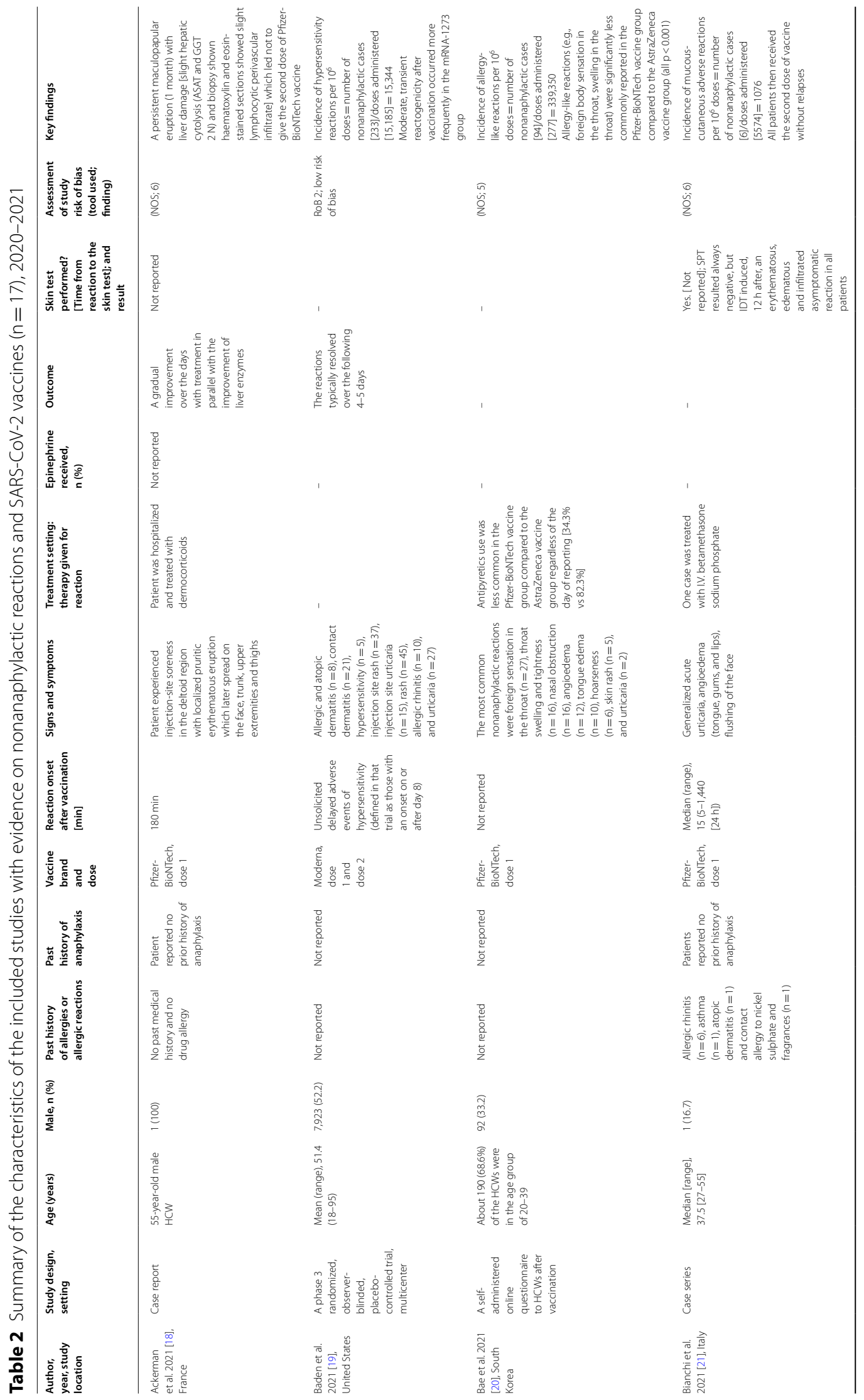




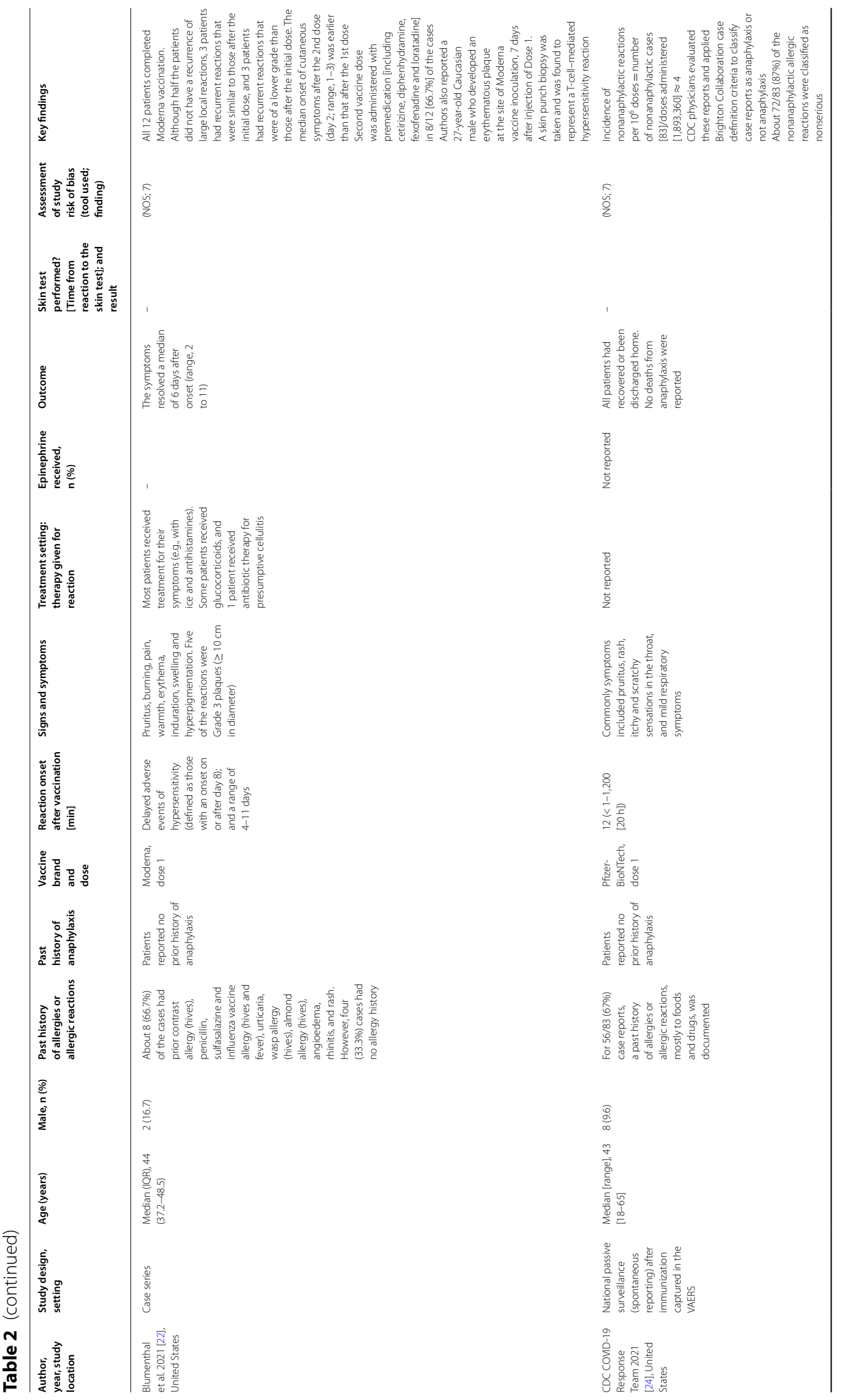




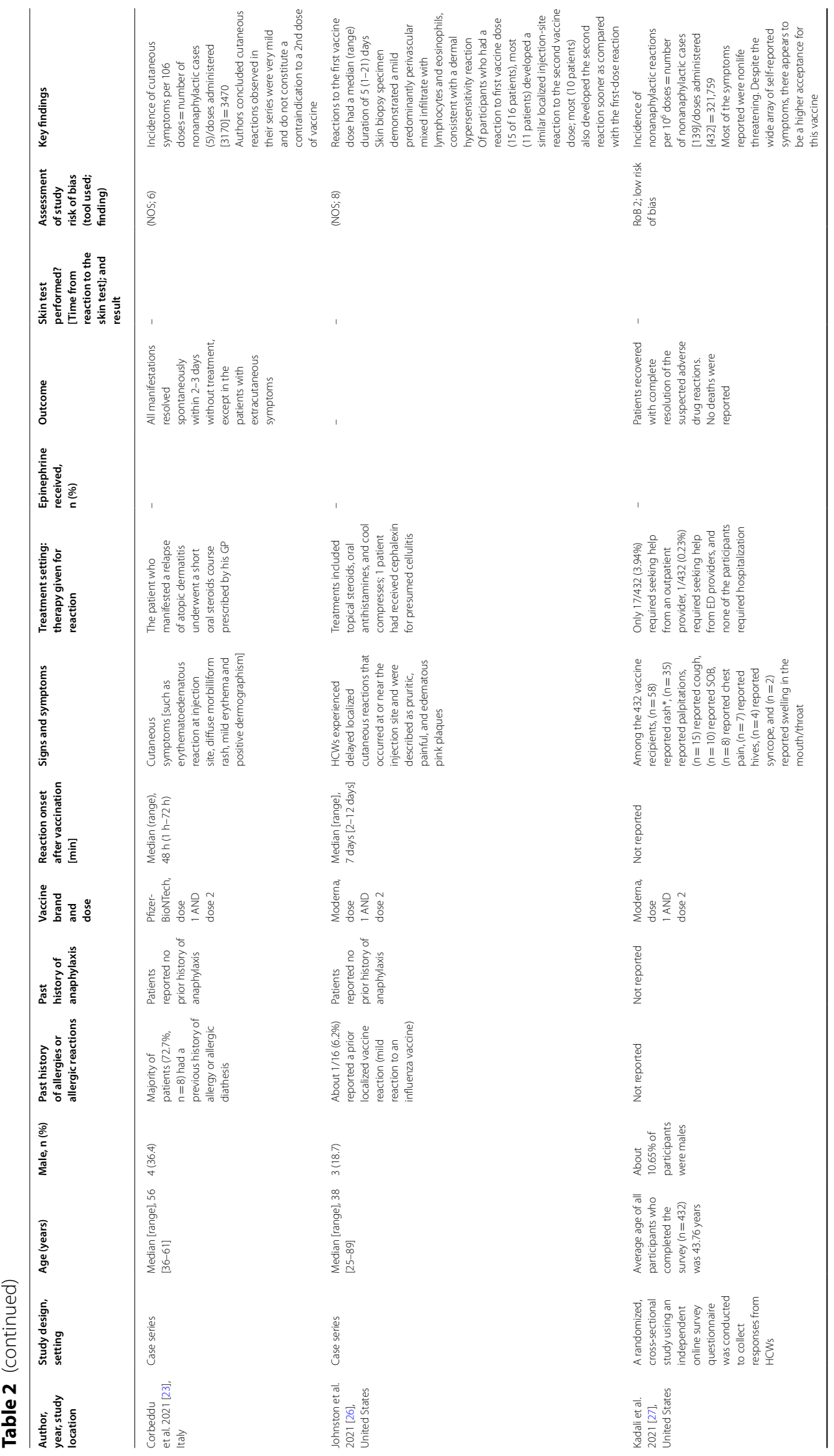




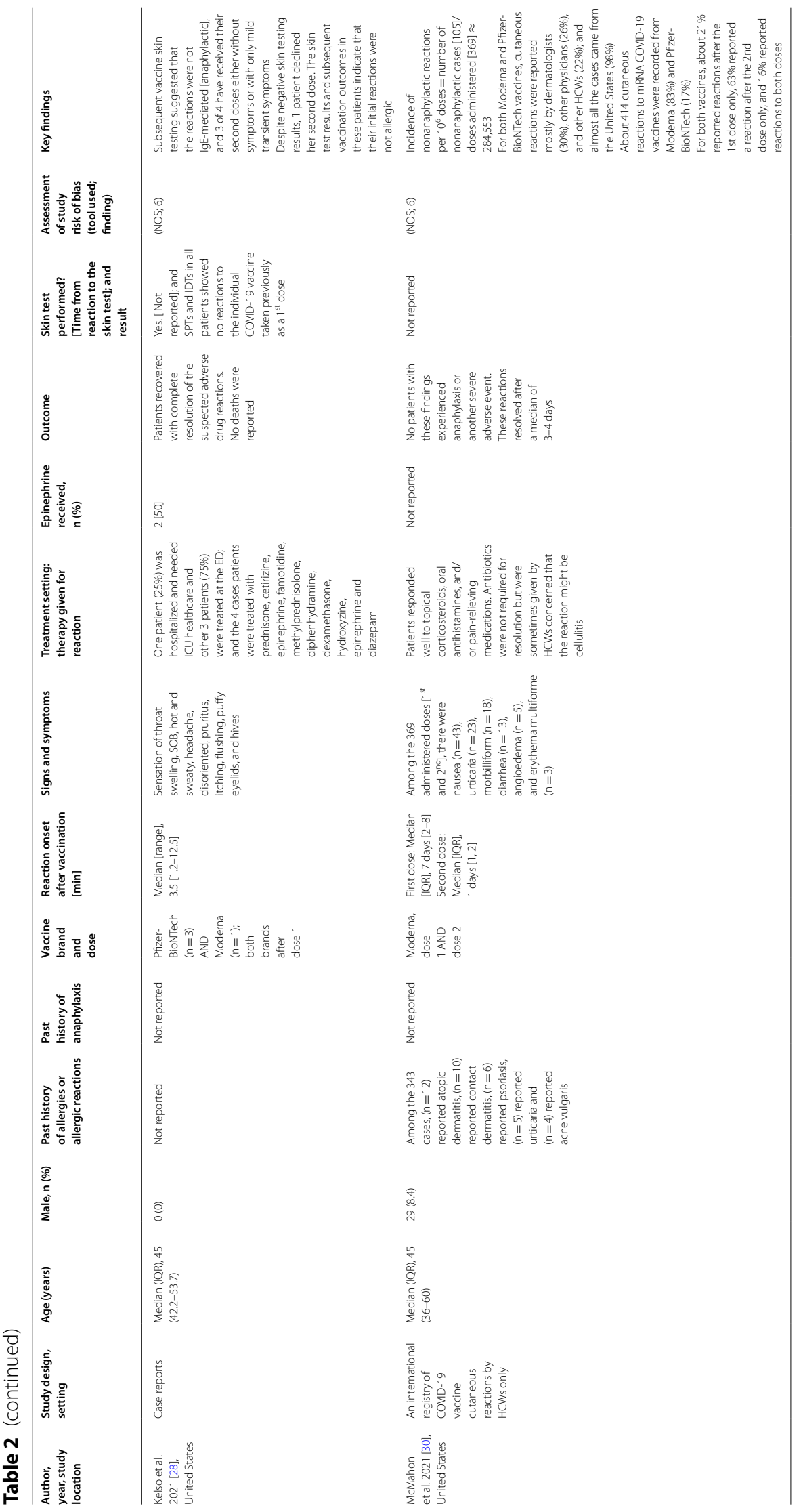




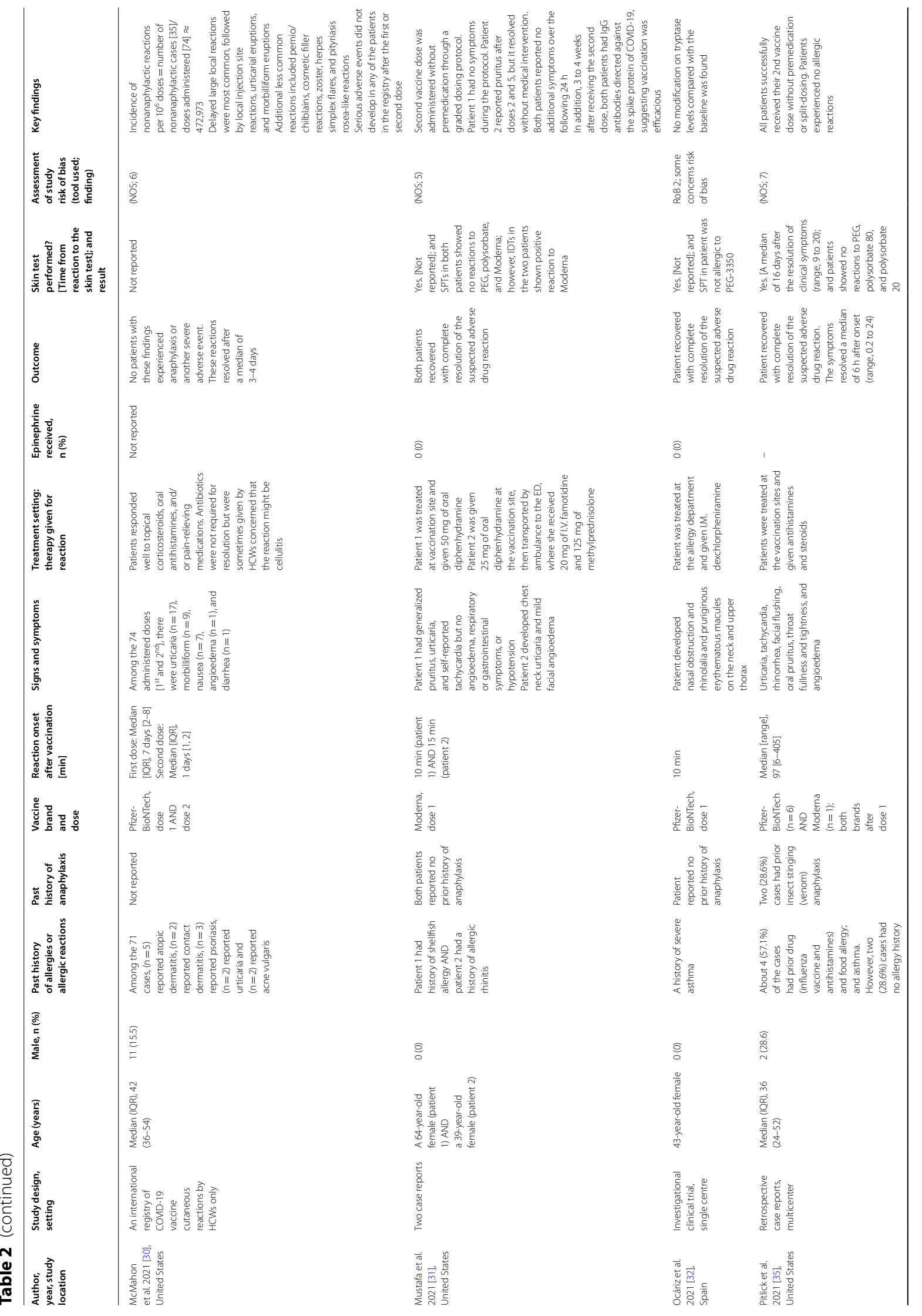




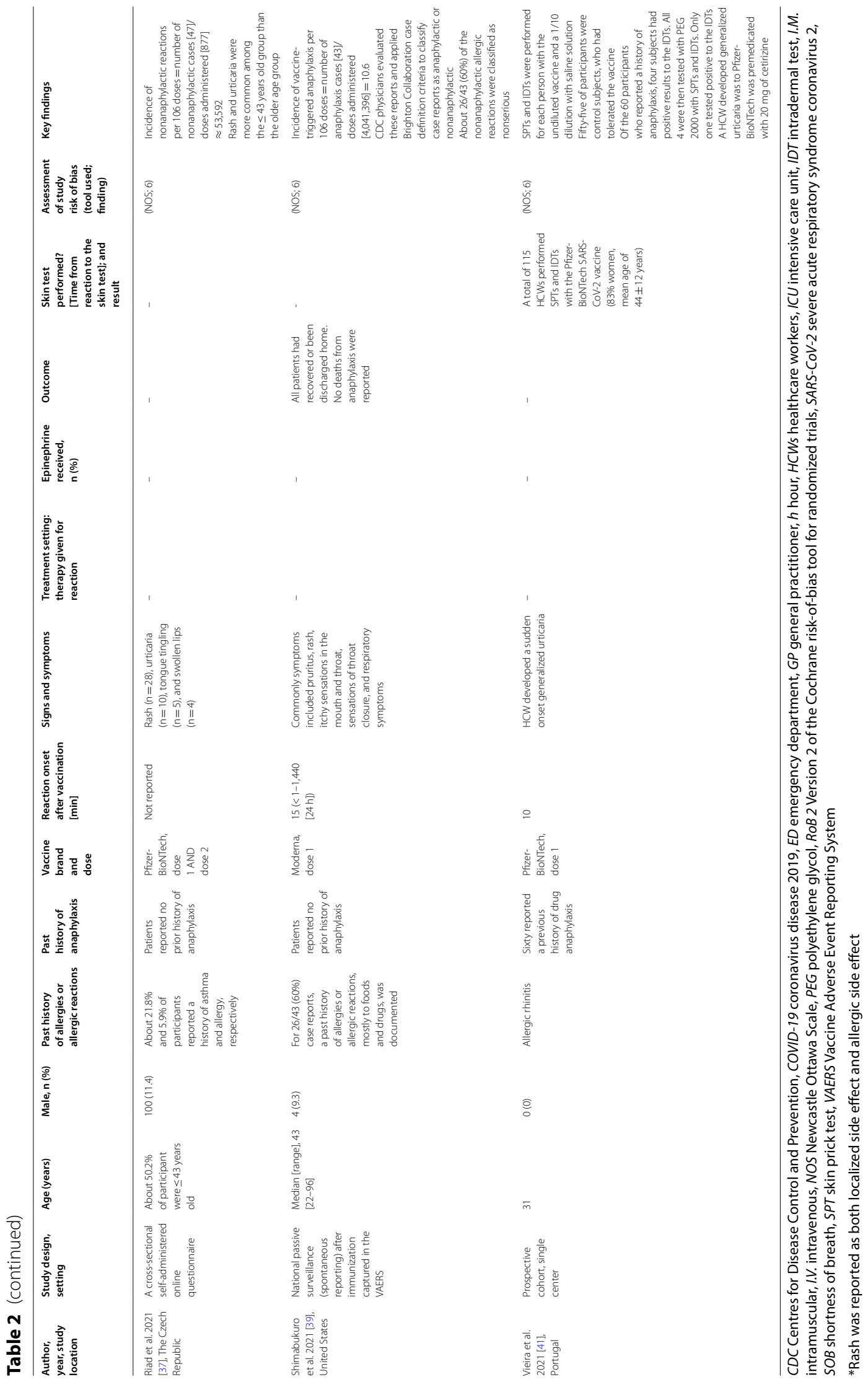




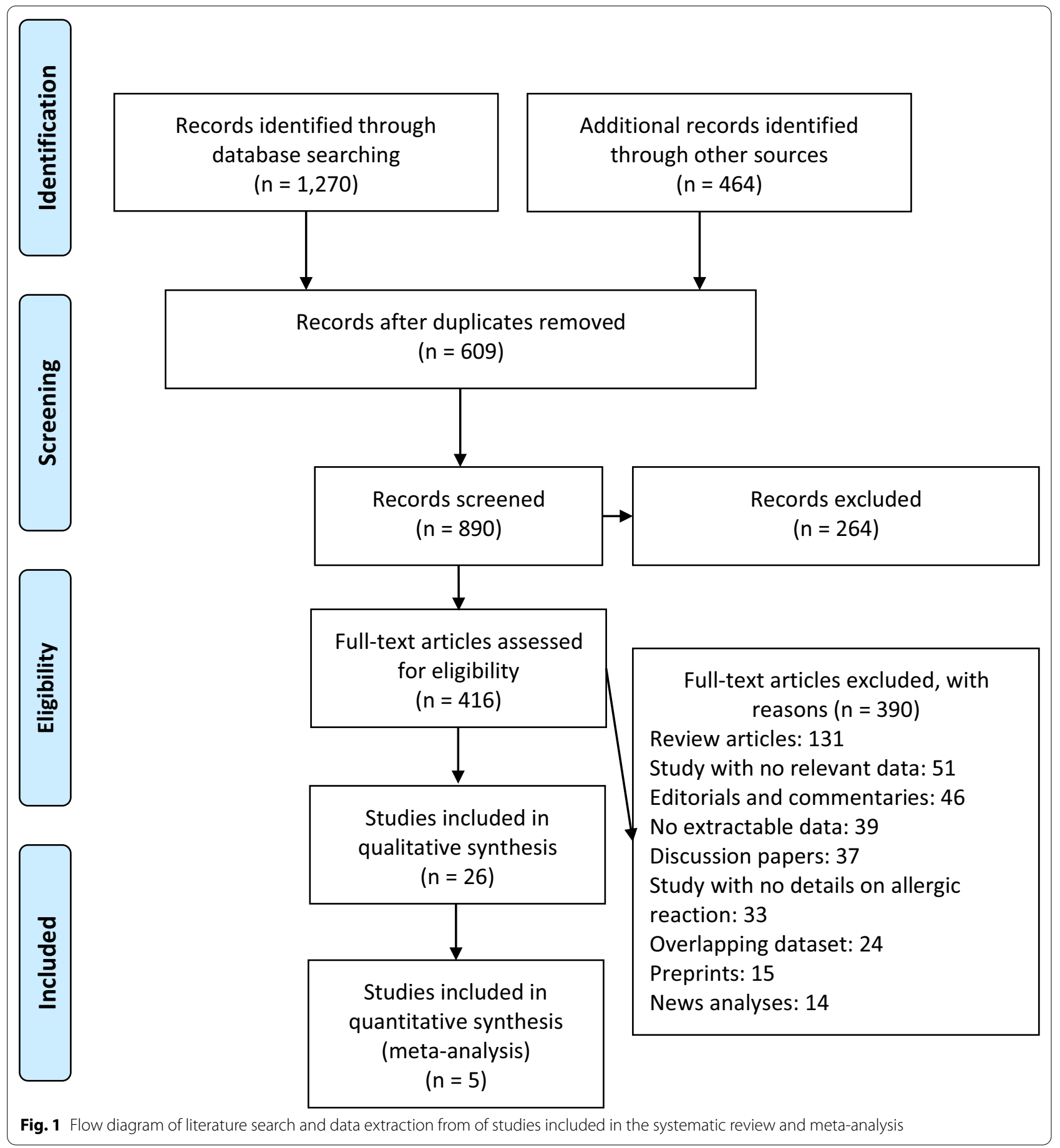

detailed characteristics of the included studies are shown in Tables 1 and 2. Among the included studies, 12 reported anaphylaxis reactions $[22,25,27,29,33-36$, 38-40], 17 reported nonanaphylactic reactions [18-24, 26-28, 30-32, 35, 37, 39, 41], and 3 studies reported both anaphylactic and nonanaphylactic reactions (27, $35,40)$. The majority of studies reporting incidence rates of anaphylaxis and nonanaphylactic reactions were conducted based on registry databases $[22,24,30,33$, $39,40]$, and most were from hospital and/or emergency department admission databases [18, 19, 21-23, 25-28, $30-36,38-41]$. A total of 26,337,421 mRNA SARS-CoV-2 vaccines recipients [Pfizer-BioNTech $(\mathrm{n}=14,505,399)$ and Moderna $(n=11,831,488)]$ were included in the 
systematic review and meta-analysis, $89.1 \%$ [23] of whom were part of the US-VAERS [24, 30, 39, 40] and Ontario's vaccine safety surveillance system to report anaphylactic and nonanaphylactic events [33]. Anaphylactic and nonanaphylactic reactions were reported by vaccine recipients via an online self-administered survey $[20,22$, $27,29,37]$; and only few studies in which anaphylactic events received through electronic health records were reviewed by allergists and immunologists [22] or physicians with unspecified medical specialty [39, 40]. Only few nonanaphylactic reactions were reported by dermatologists, other physicians, and other HCWs [30]. There were 8 case report $[18,25,28,31,34-36$, $38], 5$ cohort $[20,22,29,37,41], 4$ case series [2123, 26], 2 randomized controlled trial $[19,32]$ and 1 randomized cross-sectional [27] studies. These studies were conducted in United States $(n=15)$, Italy $(n=3)$, United Kingdom $(n=2)$, Canada $(n=1)$, France $(n=1)$, South Korea $(n=1)$, Spain $(n=1)$, Portugal $(n=1)$, and Czech Republic $(\mathrm{n}=1)$. Only 3 studies were performed with a multi-centre design [19, 22, 35]. The median NOS score for these studies was 6 (range, 5-7). Among the 26 included studies, 22 studies were moderate-quality studies (i.e., NOS scores were between 5 and 7) [18-25, $27-39,41]$ and 4 studies demonstrated a relatively high quality (i.e., NOS scores $>7$ ) [22, 26, 39, 40]; Tables 1 and 2.

Five and three studies exclusively reported anaphylaxis events in vaccine recipients of Pfizer-BioNTech [25, 34, 36, 38, 39] and Moderna [27, 35, 39], respectively; and four studies reported on anaphylactic reactions after the administration of both mRNA vaccines [22, 29, 33, 40]. Nonanaphylactic reactions were reported in patients after receiving Pfizer-BioNTech $[18,20,21,23,24$, 32, 37, 41] or Moderna [19, 22, 26, 27, 31, 39]; and few studies reported on nonanaphylactic reactions due to the vaccination by both COVID-19 vaccines [28, 30, 35]. Most studies described anaphylactic and nonanaphylactic reactions after receiving first dose of vaccine $[18,20-22$, $24,25,31,32,34-36,38,39,41]$; however, reactions were also reported after the second dose [19, 23, 26-30, 37], and in few studies the given dose was unknown $[27,33$, 40].

Essential to exclude the presence of mastocytosis and to characterize the anaphylactic events that might occurred during vaccination, only four studies reported measurement of tryptase levels in patients who suffered anaphylactic reactions $(22,34,36,38)$; Tables 1 and 2.

\section{Incidence of anaphylactic and nonanaphylactic reactions to mRNA COVID-19 vaccines}

Five and six studies offered varying estimates of incidence rates for the occurrence of anaphylaxis to
Pfizer-BioNTech [22, 29, 33, 39, 40] and Moderna [22, $27,29,33,39,40]$ vaccines; while six and four studies presented varying estimates of incidence rates for the occurrence of nonanaphylactic reactions to PfizerBioNTech [20, 21, 23, 24, 30, 37] and Moderna [19, 27, 30,39] vaccines; respectively, as shown in Tables 1 and 2 .

The incidence rates for all-cause anaphylaxis to both vaccine brands ranged from 2.5 to 7,067 per one million doses administered [22, 27, 29, 33, 39, 40]; while incidence rates for all-cause nonanaphylactic reactions to both vaccines ranged from 10.6 to 472,973 per one million doses administered [19-21, 23, 24, 27, 30, 37, 39]. The overall pooled prevalence estimate of anaphylaxis to both vaccines was 5.58 (95\% CI 3.04-8.12, $I^{2}=76.32 \%$, $p=0.00$ ), while the overall pooled prevalence estimate of nonanaphylactic reactions to both vaccines was 89.53 (95\% CI $-11.87-190.94, I^{2}=97.08 \%, p=0.00$ ). Vaccination with Pfizer-BioNTech resulted in higher anaphylactic reactions compared to Moderna (9.31, 95\% CI 4.23 to $14.40, I^{2}=52.55 \%$ versus 3.42 , $95 \%$ CI $1.42-$ $5.41, I^{2}=49.43 \%$ ), as shown in Fig. 2. However, lower incidence of nonanaphylactic reactions was associated with Pfizer-BioNTech compared to Moderna (75.27, 95\% CI $-48.28-198.82, I^{2}=0.77 \%$ versus $99.01,95 \%$ CI $\left.-49.77-247.80, I^{2}=0.37 \%\right)$, as shown in Fig. 3 . The funnel plots for possible publication bias for the pooled effect sizes to determine the incidence of anaphylaxis and nonanaphylactic reactions associated with mRNA COVID-19 immunization based on mRNA vaccine type appeared asymmetrical on visual inspection, and Egger's tests confirmed asymmetry by producing $p$ values $<0.05$; Figs. 4 and 5.

\section{Characteristics of the patients, history of allergy, and co-morbid conditions}

The median or mean patient age ranged from $\geq 18$ to 96 years across studies (i.e., only adult patients were included). There was an increased female predominance in vaccine-associated anaphylactic and nonanaphylactic reactions in most of the studies [20-41]. The key triggers to anaphylactic reactions identified in these studies included foods $[22,25,33,36,39,40]$, medications [22, $25,33,38-40]$, stinging insects [39] or jellyfish [40], cosmetics and detergents [36, 38], household products [33], and latex [40]. Nonanaphylactic reactions were triggered less by foods [22, 24, 31, 35, 39], drugs [22, 24, $26,35,39,41]$, insect stinging [22], and contrast media [22]. Previous history of anaphylaxis [22, 25, 33, 35, $38-41]$; and comorbidities such as asthma [21, 32, 34, $35,37]$, allergic rhinitis [21, 22, 31, 35, 41], atopic and contact eczema/dermatitis [21,30,34] and psoriasis [30] and cholinergic urticaria [34] were also found to be important. 


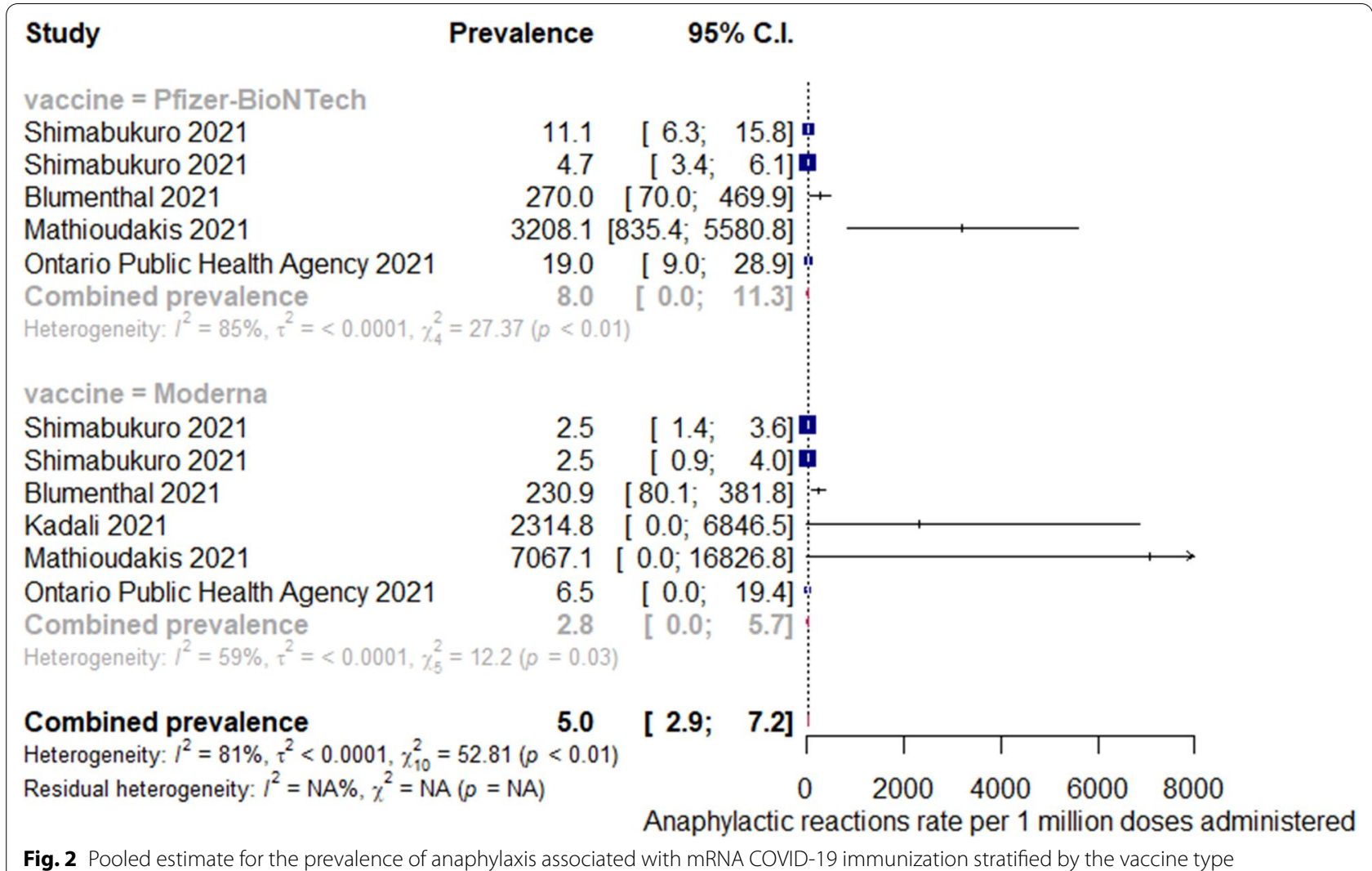

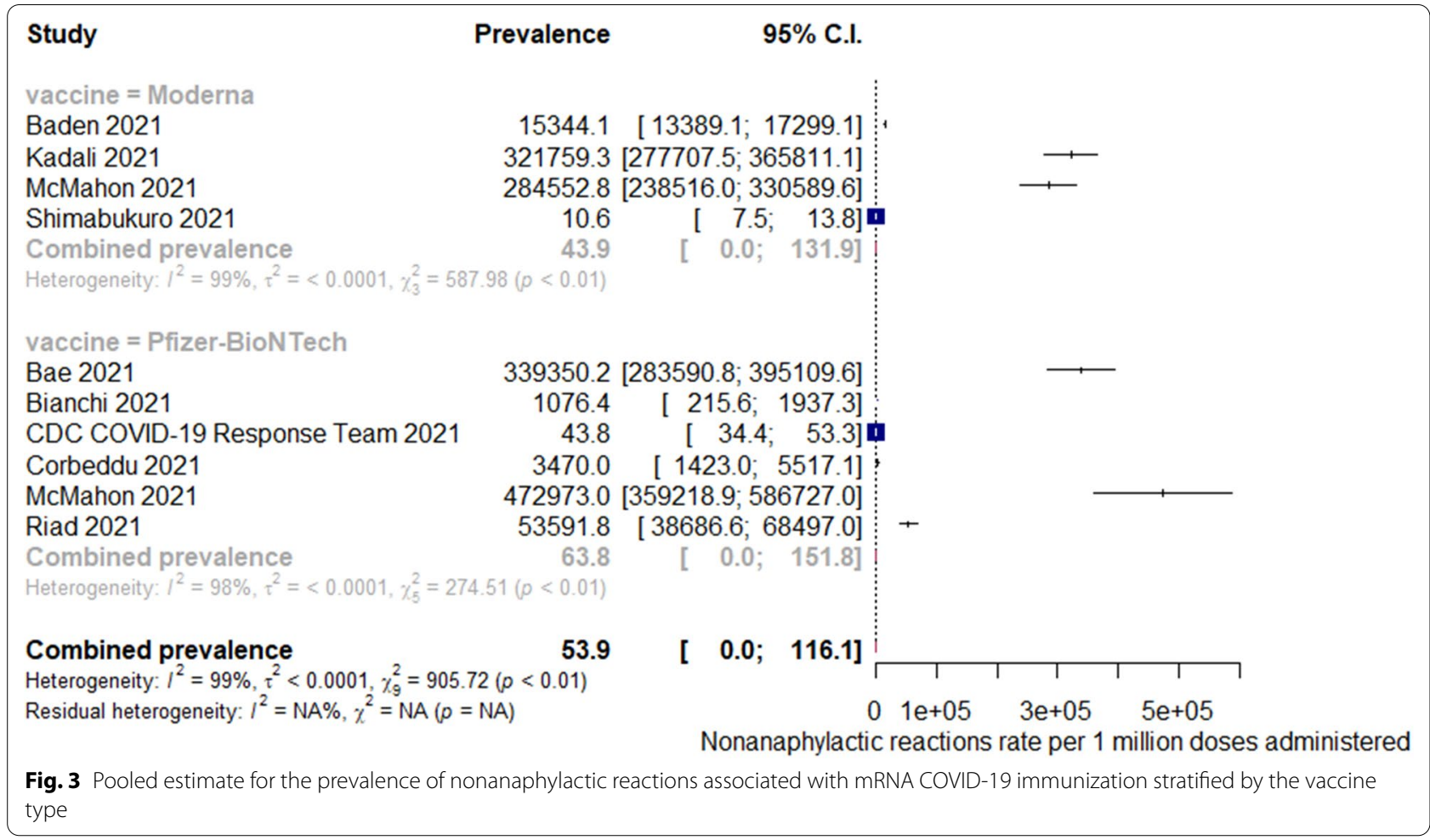




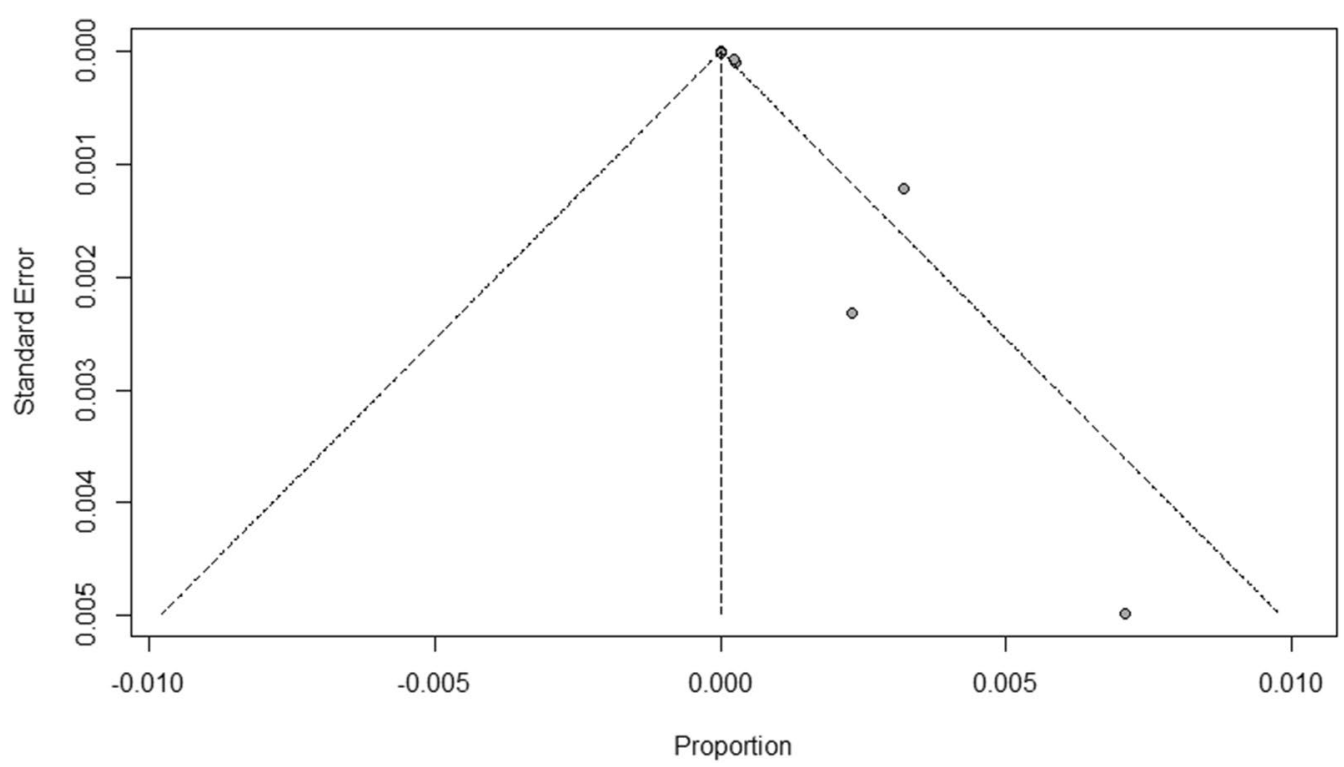

Fig. 4 Funnel plots to evaluate publication bias for the pooled effect size to determine the prevalence of anaphylaxis associated with mRNA COVID-19 immunization based on mRNA vaccine type

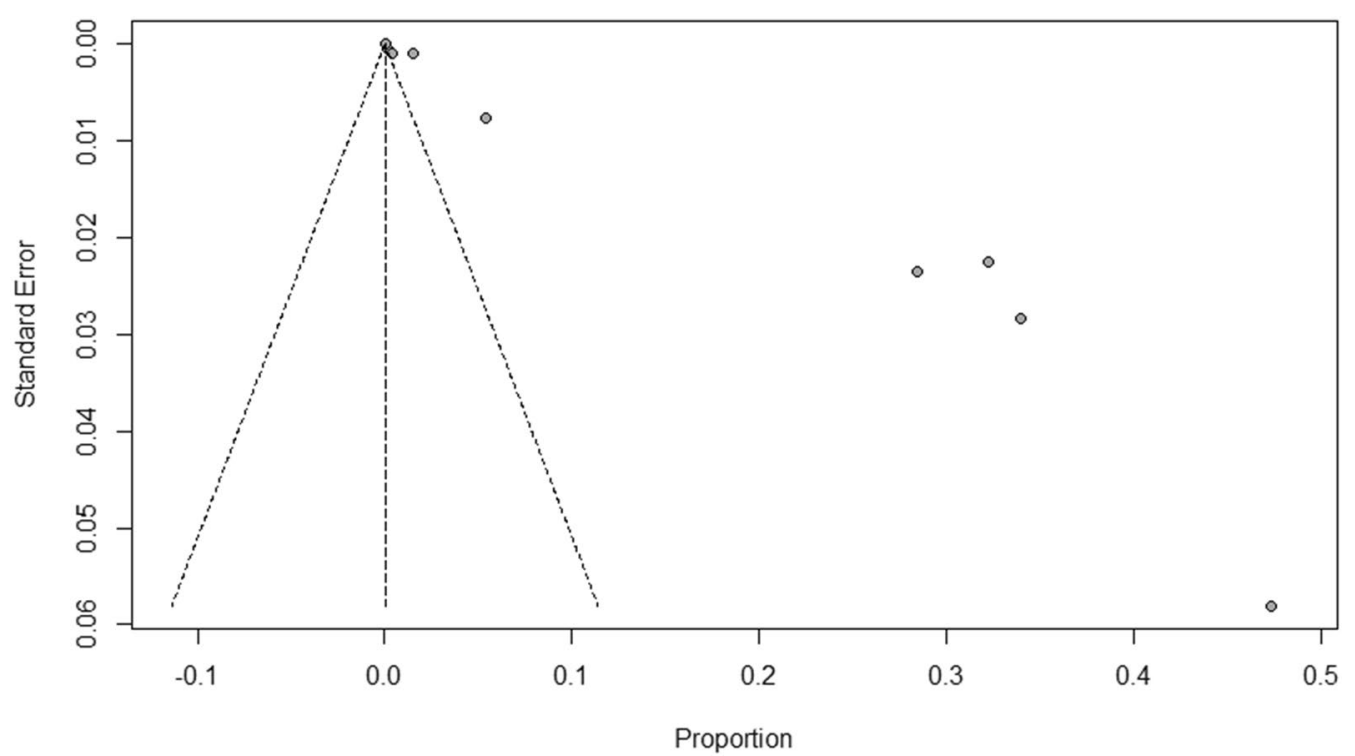

Fig. 5 Funnel plots to evaluate publication bias for the pooled effect size to determine the prevalence of nonanaphylactic reactions associated with mRNA COVID-19 immunization based on mRNA vaccine type

\section{Reaction onset after vaccination, clinical features}

\section{and severity of the reaction}

Anaphylactic reactions onsets after inoculation by both vaccines were within 1-5 $\min [34,38],>5-30 \mathrm{~min}[22$, $25,33,35,39,40],>30$ min [36], or not stated in cases $[27,29]$; whereas nonanaphylactic reactions occurred within $<5 \min$ [28], > 5-30 $\min [21,24,31,32,39,41]$, > 31 to $\leq 1,440 \min [18,30,35], \geq 2-8$ days $[19,22,23,26$, $30]$, or not reported in cases [20, 27, 37]. The common presenting signs and symptoms in anaphylactic cases were pruritic hives [22, 25, 34, 39, 40]; throat closure [22, 25, 38, 39] or pruritis [35]; angioedema [22, 35, 39, $40]$; wheezing [22, 25, 35, 39]; nausea and vomiting [22, $34,39,40]$; tachycardia; rash [39, 40]; hypotension [22, 
39]; cough [22, 38]; dyspnea [22, 25]; tongue swelling [34, 39]; flushing [34]; diarrhea [22]; light headedness [34]; shortness of breath [34]; respiratory failure [39]; periorbital oedema [39]; loss of consciousness [38]; hypoxemia [38]; and erythematous spots on face and neck, slurred mouth, and hoarseness [36] (Table 1). The definition from Brighton criteria [42] was the most widely applied definition in included studies $(\mathrm{n}=7)[22$, $25,33,35,39,40]$; although 1 study [22] relied on NIAID/ FAAN criteria [43] and Brighton criteria [42] to define anaphylaxis. On severity assessment, most anaphylactic patients belonged to Brighton Level $2(\mathrm{n}=55)$ [22, 33, 39, 40]; Brighton Level $1(\mathrm{n}=50)$ [22, 25, 33, 35, 39, 40]; National Institute of Allergy and Infectious Diseases/ Food Allergy and Anaphylaxis Network [NIAID/FAAN] Grade II $(n=9)$ [22] or Grade I $(n=7)$ [22]; and Brighton Level $3(n=6)[22,40]$ at the time of presentation.

Most frequently-reported nonanaphylactic reactions following COVID-19 vaccines were cutaneous reactions $(18-20,23,24,27,32,35,39)$ and delayed large local reactions $(19,22,26,30)$. Both cutaneous and delayed reactions frequently took the form of injection site swelling and/or pain, erythema, and rash. Another commonly-reported nonanaphylactic reaction was urticaria $[21,22,28,30,31,37,41]$. These common reactogenicity symptoms occurred in lower rates following the second vaccine dose $[22,26,30]$. There were less frequent and unusual cutaneous reactions to the COVID-19 vaccines such as: erythema multiforme, pernio/chilblains, filler swellings, and exacerbation of viral infections such as herpes zoster and herpes simplex in addition to the occurrence of pityriasis rosea-like reactions $(27,30)$.

\section{Therapeutic interventions and treatment outcome}

Epinephrine was administered in 99 anaphylactic cases [22, 25, 33, 34, 38-40] and four studies did not state its use $[27,29,35,36]$. Epinephrine was given to two cases only in all patients who suffered nonanaphylactic reactions (28). Corticosteroids [35, 36, 38], antihistamines [34-36, 38], and intravenous fluids $[25,36,38]$ were used in anaphylactic cases; and very few patients who suffered anaphylaxis required ventilatory support [36, 39, 40] or endotracheal intubation [39, 40]. Most of the nonanaphylactic reactions participants received corticosteroids [18, 21-23, 26, 28, 30, 31, 35] and/or antihistamines [22, 26, 28, 30-32, 35]; and few received antibiotics $[22,26,30], \mathrm{H}_{2}$ antagonists [28, $31]$, or antipyretics $[20,30]$. No case fatalities due to anaphylactic and nonanaphylactic reactions were noted in all included studies [18-41]; and all patients had recovered or been discharged home.

\section{Allergen testing and SARS-CoV-2 vaccine challenge}

Allergens were tested in 132 cases [21, 28, 31, 32, 34$36,38,41]$. Skin prick tests and intradermal tests were performed in 130/132 (98.5\%) and 129/132 (97.7\%) cases, respectively. Only one study reported the use of Basophil Activation Test [42] which identified patient's reactivity towards polyethylene glycol [PEG] [36]. Seventeen positive allergen skin testing were linked to the following: Pfizer-BioNTech [10, 21, 41]; polyethylene glycol [5, 38, 41]; Moderna [1,31]; and house dust mites, peach and fruits $[1,36]$. Seventy-eight negative skin testing were linked to the Pfizer-BioNTech (66) [21, 28, 34, 38, 41]; polyethylene glycol [5, 31, 32, 34, 35]; polysorbate 20 and 80 [4, 31, 34, 35, 38]; and Moderna [3, 28, 31] (Tables 1 and 2).

Two patients who had anaphylaxis following the first dose of COVID-19 vaccine successfully received the second dose without premedication or split-dosing in consultation with an allergist. These two only exhibited mild nausea and minor lip or tongue tingling on second dose administration $[34,35]$ (Table 1 ). A total of 39 study participants with reported history of nonanaphylactic reactions to COVID-19 mRNA vaccines were challenged with a second dose [21-23, 28,35], and none were given the vaccine by split-dosing; and only 12 participants received premedication [22] and most patients then received the second dose of vaccine without a relapse of large local reactions $(21-23,28,35)$. However, 3 patients had recurrent reactions similar to those after the initial dose and 3 patients had recurrent reactions that were of a lower grade than after the initial dose [22] (Table 2).

\section{Discussion}

This study involving 26,337,421 mRNA SARS-CoV-2 vaccines recipients [Pfizer-BioNTech $(\mathrm{n}=14,505,399)$ and Moderna $(n=11,831,488)]$ from 26 observational studies found an overall pooled prevalence estimate of anaphylaxis to both vaccines was 5.58 per million doses administered (95\% CI 3.04 to 8.12 ), while the overall pooled prevalence estimate of nonanaphylactic reactions to both vaccines was 89.53 per million doses administered (95\% CI - 11.87-190.94). Vaccination with Pfizer-BioNTech resulted in higher anaphylactic reactions compared to Moderna (9.31 per million doses administered, 95\% CI $4.23-14.40$ versus 3.42 per million doses administered, 95\% CI 1.42-5.41), however, lower incidence of nonanaphylactic reactions was associated with Pfizer-BioNTech compared to Moderna (75.27 per million doses administered, 95\% CI - 48.28-198.82 versus 99.01 per million doses administered, 95\% CI - 49.77-247.80). Nevertheless, these findings on incidence rates of anaphylactic and nonanaphylactic 
reactions in COVID-19 mRNA vaccine recipients were limited to case reports, case series and cohort studies; and majority of studies reporting incidence rates of anaphylactic and nonanaphylactic reactions were conducted based on registry databases, and may not reflect the overall incidence rates of anaphylactic and nonanaphylactic reactions as the vast majority were from hospital and/or emergency department admission databases. We found a wide variation in the prevalences of reported anaphylactic and nonanaphylactic reactions across different studies, because they assessed different populations and settings, and used different methods. Thus, it is important that any studies in the future use a consistent and accurate definitions of anaphylactic and nonanaphylactic reactions. Use of the correct epidemiological method to define prevalence would help to identify any true difference between countries, and help to provide an overall estimate of prevalence.

Across the included studies, the most commonly identified risk factors for anaphylactic and nonanaphylactic reactions to SARS-CoV-2 mRNA vaccines were being female and previous history of atopy. Based on the published studies included in our review, evidence suggests females are much more susceptible to anaphylactic and nonanaphylactic reactions. Formation of a polyethylene glycol (PEG)-conjugated lipid derivative is hypothesized to cause COVID-19 mRNA vaccineassociated anaphylactic and nonanaphylactic reactions [44]. Sensitization to PEG is more common in women due to the relatively frequent exposure to PEG-containing products, such as cutaneous exposure to cosmetics or the use of medications such as contraceptive injections and explains female predominance in the reported cases of vaccine-associated anaphylactic and nonanaphylactic reactions [45]. Another possible explanation includes hormonal differences such as the role of estrogen which may be an important factor in allergic immunological responses [45].

Consistent with previous studies, our review found that foods, drugs or therapeutic agents, contrast media, stinging insects or jellyfish, cosmetics, detergents, household products, and latex are the most common triggers of anaphylactic and nonanaphylactic reactions induced by mRNA COVID-19 vaccines [21-23, 38, 46]. Previous history of anaphylaxis; and comorbidities such as asthma, allergic rhinitis, atopic and contact eczema/ dermatitis and psoriasis and cholinergic urticaria were also described by other investigators as elicitors for anaphylactic and nonanaphylactic reactions to mRNA COVID-19 vaccines $[47,48]$. Nevertheless, assessment by an allergist is NOT required for people with a history of unrelated allergies, including to allergies to foods, drugs, insect venom or environmental allergens and COVID-19 vaccines can be administered in these individuals without any special precautions [49].

The occurrence of anaphylaxis is of a particular concern in the use of newly authorized COVID-19 vaccines. The diagnosis of anaphylaxis requires professional judgment, such as case-by-case interpretation using validated diagnostic criteria for anaphylaxis $[42,43]$ as anaphylaxis occurrence may have a profound effect on the quality of life of the sufferer and their family [50]. It is important to identify those who might be at an increased risk of anaphylaxis in order to reduce morbidity, and provide successful management plans. Given the importance of anxiety as a contributor to the quality of life impact of COVID-19 vaccines allergy, our finding that fatal vaccine anaphylaxis incidence is relatively nil may be important information for vaccine-allergic people and their carers. Although anaphylaxis after mRNA SARS-CoV-2 vaccination is very rare, its immediate onset [usually within minutes] and life-threatening nature require that all $\mathrm{HCWs}$ and facilities providing vaccinations have procedures in place for anaphylaxis management. Patients who have experienced anaphylaxis should be referred to an allergy/immunology specialist to confirm the diagnosis, confirm or determine the causes(s), and determine relevant patient risk factors for severe or fatal anaphylaxis (e.g., comorbidities or concurrent medications that could be modified to reduce the patient's risk of recurrences in the future). In someone with a suspected or confirmed allergy to a SARS-CoV-2 vaccine or one of its components for whom an additional dose is required, choices include deferral of the second vaccine dose, selection of an alternative vaccine with a different platform and excipients, and the administration of the same vaccine using a graded vaccine administration protocol [51].

Healthcare workers need to differentiate the occurrence of anaphylaxis from the development of vasovagal reactions and anxiety-related symptoms [52]. While it is important to recognize and treat anaphylaxis, it is equally important not to label these other conditions as anaphylaxis, particularly when there are no objective findings. Localized cutaneous reactions were common following the mRNA vaccines and include urticarial and morbilliform eruptions which may reflect immediate hypersensitivity but have rarely been associated with anaphylaxis. There are infrequent reports of erythema multiforme, pernio/chilblains, cosmetic filler reactions, zoster, herpes simplex flares, and pityriasis rosea-like reactions, mainly occurring in high-risk patient groups $[27,30]$. Ultimately, the identified cutaneous reactions are largely self-limited and should not discourage vaccination. Existing reports should reassure patients of the overall compelling safety profiles and benignity 
of skin reactions following the mRNA SARS-CoV-2 vaccines. Mimics of anaphylaxis should not discourage vaccination against the COVID-19 pandemic and a high rate of SARS-CoV-2 vaccines uptake across all sectors of worldwide societies is a priority public health goal. These findings should provide reassurance to HCWs and to vaccine recipients and promote confidence in the safety of COVID-19 vaccines.

\section{Limitations}

There are several limitations to our findings. First, the quality of data submitted by reporters on anaphylactic and nonanaphylactic reactions mostly through registry databases and online questionnaires varies widely and never used standardized data collection methods. Second, most of the included studies relied on the clinical history for the diagnosis of anaphylactic and nonanaphylactic reactions. Third, some studies do not provide denominator data to calculate the incidence rates of anaphylactic and nonanaphylactic reactions; therefore, estimating accurate incidence rates by interpreting these studies databases was not possible. Fourth, the quality and completeness of the reports included in few studies might not be optimal, thus making the assessment of causality challenging. The fifth limitation is the exclusion of non-English language studies.

\section{Conclusion}

The prevalence of COVID-19 mRNA vaccineassociated anaphylaxis is very low; and nonanaphylactic reactions occur at higher rate, however, cutaneous reactions are largely self-limited. Both anaphylactic and nonanaphylactic reactions should not discourage vaccination.

\footnotetext{
Abbreviations

COVID-19: Coronavirus disease 2019; IDT: Intradermal test; NOS: NewcastleOttawa scale; NIAID/FAAN: National Institute of Allergy and Infectious Diseases/Food Allergy and Anaphylaxis Network; PEG: Polyethylene glycol; PRISMA: Preferred Reporting Items for systematic reviews and meta-Analyses; RoB 2.0: Revised Cochrane risk of bias tool; SARS-CoV-2: Severe acute respiratory syndrome coronavirus 2; SPT: Skin prick test; VAERS: Vaccine Adverse Event Reporting System.

\section{Acknowledgements}

We would like to thank authors and their colleagues who contributed to the availability of evidence needed to compile this article. We would also like to thank the reviewers for very helpful and valuable comments and suggestions for improving the paper.
}

\section{Authors' contributions}

SA, AA, ZA, AR, and JA contributed equally to the systematic review. SA, AA, ZA and $A R$ were the core team leading the systematic review. SA, AA, AR, RT, MAAand ZA identified and selected the studies. HMA, ASA, TTA, GA, and AMA did the quality assessment of the studies. SA, AAA, ZAA, MAA, EAA, and AKB collected the data. SA, HM, MA, KD, and $A A O$ analysed the data. SA, AA, AR, ZA and JA drafted the manuscript. All authors approved the final version of the manuscript. The corresponding author attests that all listed authors meet authorship criteria and that no others meeting the criteria have been omitted. All authors read and approved the final manuscript.

Funding

None.

Availability of data and materials

Data are available upon request, please contact author for data requests.

\section{Declarations}

Ethics approval and consent to participate

This review is exempt from ethics approval because we collected and synthesized data from previous clinical studies in which informed consent has already been obtained by the investigators.

\section{Consent for publication}

All authors agreed to this publication.

\section{Competing interests}

The authors declare that they have no competing interests.

\section{Author details}

${ }^{1}$ Administration of Pharmaceutical Care, Al-Ahsa Health Cluster, Ministry of Health, Rashdiah Street, P. O. Box 12944, Al-Ahsa 31982, Saudi Arabia. ${ }^{2}$ Research Center, Almoosa Specialist Hospital, Al-Ahsa, Saudi Arabia. ${ }^{3}$ College of Nursing, Princess Norah Bint Abdul Rahman University, Riyadh, Saudi Arabia. ${ }^{4}$ School of Nursing, University of Wollongong, Wollongong, Australia. ${ }^{5}$ Division of Allergy and Immunology, College of Medicine, King Faisal University, Al-Ahsa, Saudi Arabia. ${ }^{6}$ Molecular Diagnostic Laboratory, Johns Hopkins Aramco Healthcare, Dhahran, Saudi Arabia. ${ }^{7}$ Department of Public Health and Nutrition, The University of Haripur, Haripur 22610, Pakistan. ${ }^{8}$ Department of Medicine Keystone Health, Penn State University School of Medicine, Hershey, PA, USA. ${ }^{9}$ Department of Medicine, Wellspan Chambersburg and Waynesboro (Pa.) Hospitals, Chambersburg, PA, USA.

${ }^{10}$ Palliative Care Department, King Fahad Medical City, Riyadh, Saudi Arabia. ${ }^{11}$ Department of Psychiatry, Prince Saud Bin Jalawi Hospital, Al-Ahsa, Saudi Arabia. ${ }^{12}$ Department of Pharmacy, King Fahad Hofuf Hospital, Al-Ahsa, Saudi Arabia. ${ }^{13}$ Administration of Compliance, Al-Ahsa Health Affairs, Ministry of Health, Al-Ahsa, Saudi Arabia. ${ }^{14}$ Department of Pharmacy, Hereditary Blood Diseases Centre, Al-Ahsa, Saudi Arabia. ${ }^{15}$ Department of Pharmacy, Maternity and Children Hospital, Al-Ahsa, Saudi Arabia. ${ }^{16}$ Primary Care Medicine, Al-Ahsa Health Cluster, Ministry of Health, Al-Ahsa, Saudi Arabia. ${ }^{17}$ Department of Pharmacy, Prince Saud Bin Jalawi Hospital, Al-Ahsa, Saudi Arabia. ${ }^{18}$ Department of Cardiac Sciences, King Abdulaziz Medical City, Ministry of National Guard Health Affairs, Jeddah, Saudi Arabia. ${ }^{19}$ Department Cardiac Sciences, College of Medicine, King Saud bin Abdulaziz University for Health Sciences, Ministry of National Guard Health Affairs, Jeddah, Saudi Arabia. ${ }^{20}$ Department of Medical Research, King Abdullah International Medical Research Center, Ministry of National Guard Health Affairs, Jeddah, Saudi Arabia. ${ }^{21}$ Department of Medicine, Royal College of Surgeons in Ireland, Bahrain, Kingdom of Bahrain. ${ }^{22}$ Department of Infectious Diseases, Royal Medical Services, Bahrain Defence Force Hospital, Riffa, Kingdom of Bahrain. ${ }^{23}$ Division of Pathology, ICAR-Indian Veterinary Research Institute, Izatnagar, Bareilly, Uttar Pradesh 243122, India. ${ }^{24}$ Infectious Disease Unit, Specialty Internal Medicine, Johns Hopkins Aramco Healthcare, Dhahran, Saudi Arabia. ${ }^{25}$ Infectious Disease Division, Department of Medicine, Indiana University School of Medicine, Indianapolis, IN, USA. ${ }^{26}$ Infectious Disease Division, Department of Medicine, Johns Hopkins University School of Medicine, Baltimore, MD, USA. ${ }^{27}$ College of Medicine, Alfaisal University, Riyadh, Saudi Arabia. ${ }^{28}$ Research Center, Dr. Sulaiman Al Habib Medical Group, Riyadh, Saudi Arabia.

Received: 7 July 2021 Accepted: 6 October 2021 Published online: 16 October 2021 


\section{References}

1. World Health Organization. WHO Coronavirus (COVID-19) Dashboard 2021. https://covid19.who.int. . Accessed 28 May 2021.

2. United States Food and Drug Administration. Pfizer-BioNTech COVID-19 Vaccine 2021. https://www.fda.gov/emergency-preparedness-and-respo nse/coronavirus-disease-2019-covid-19/pfizer-biontech-covid-19-vacci ne. Accessed 6 Jun 2021.

3. United States Food and Drug Administration. Moderna COVID-19 Vaccine 2021. https://www.fda.gov/emergency-preparedness-and-response/ coronavirus-disease-2019-covid-19/moderna-covid-19-vaccine. Accessed 6 Jun 2021.

4. Temsah M-H, Barry M, Aljamaan F, Alhuzaimi AN, Al-Eyadhy A, Saddik B, Alsohime F, Alhaboob A, Alhasan K, Alaraj A. SARS-CoV-2 B. 1.1. 7 UK variant of concern lineage-related perceptions, COVID-19 vaccine acceptance and travel worry among healthcare workers. Front Public Health. 2021;9:617.

5. Koritala T, Hussain A, Pleshkova Y, Dondapati L, Tirupathi R, Rabaan AA, Al Mutair A, Alhumaid11 S, Al-Tawfiq12 JA, Kashyap15 R. A narrative review of emergency use authorization versus full FDA approval and its effect on COVID-19 vaccination hesitancy.

6. Dhama K, Sharun K, Tiwari R, Dhawan M, Emran TB, Rabaan AA, Alhumaid S. COVID-19 vaccine hesitancy-reasons and solutions to achieve a successful global vaccination campaign to tackle the ongoing pandemic. Hum Vaccin Immunother. 2021. https://doi.org/10.1080/21645515.2021. 1926183.

7. American Academy of Allergy A, American College of Allergy A, Joint Council of Allergy A, Parameters JTFoP. Drug allergy: an updated practice parameter. Ann Allergy Asthma Immunol. 2010;105(4):259-73.

8. Lang DM, Patadia DD. Anaphylaxis to vaccinations: a review of the literature and evaluation of the COVID-19 mRNA vaccinations. Cleve Clin J Med. 2021. https://doi.org/10.3949/ccjm.88a.ccc075.

9. Schnyder B, Pichler WJ. Mechanisms of drug-induced allergy. Mayo Clin Proc. 2009. https://doi.org/10.4065/84.3.268.

10. Su JR, Moro PL, Ng CS, Lewis PW, Said MA, Cano MV. Anaphylaxis after vaccination reported to the Vaccine Adverse Event Reporting System, 1990-2016. J Allergy Clin Immunol. 2019;143(4):1465-73.

11. Moher D, Liberati A, Tetzlaff J, Altman DG, Group P. Preferred reporting items for systematic reviews and meta-analyses: the PRISMA statement. PLoS Med. 2009;6(7):e1000097.

12. Peterson J, Welch V, Losos M, Tugwell P. The Newcastle-Ottawa scale (NOS) for assessing the quality of nonrandomised studies in metaanalyses. Ottawa: Ottawa Hospital Research Institute; 2011.

13. Sterne JA, Savović J, Page MJ, Elbers RG, Blencowe NS, Boutron I, Cates CJ, Cheng H-Y, Corbett MS, Eldridge SM. RoB 2: a revised tool for assessing risk of bias in randomised trials. BMJ. 2019. https://doi.org/10.1136/bmj. 14898.

14. Schmidt FL, Hunter JE. Meta-analysis. In: Weiner IB, editor. Handbook of psychology. Hoboke: John Wiley \& Sons Inc; 2003. p. 533-54.

15. Higgins JP, Thompson SG. Quantifying heterogeneity in a meta-analysis. Stat Med. 2002;21(11):1539-58.

16. Higgins JP, Thompson SG, Deeks JJ, Altman DG. Measuring inconsistency in meta-analyses. BMJ. 2003;327(7414):557-60.

17. Egger M, Smith GD, Schneider M, Minder C. Bias in meta-analysis detected by a simple, graphical test. BMJ. 1997;315(7109):629-34.

18. Ackerman M, Henry D, Finon A, Binois R, Esteve E. Persistent maculopapular rash after the first dose of Pfizer-BioNTech COVID-19 vaccine. J Eur Acad Dermatol Venereol. 2021. https://doi.org/10.1111/jdv. 17248

19. Baden LR, El Sahly HM, Essink B, Kotloff K, Frey S, Novak R, Diemert D, Spector SA, Rouphael N, Creech CB. Efficacy and safety of the mRNA-1273 SARS-CoV-2 vaccine. N Engl J Med. 2021;384(5):403-16.

20. Bae S, Lee YW, Lim SY, Lee J-H, Lim JS, Lee S, Park S, Kim S-K, Lim Y-J, Kim EO. Adverse reactions following the first dose of ChAdOx1 nCoV-19 vaccine and BNT162b2 vaccine for healthcare workers in South Korea. J Korean Med Sci. 2021. https://doi.org/10.3346/jkms.2021.36.e115.

21. Bianchi L, Biondi F, Hansel K, Murgia N, Tramontana M, Stingeni L. Skin tests in urticaria/angioedema and flushing to Pfizer-BioNTech SARSCoV-2 vaccine: limits of intradermal testing. Allergy. 2021. https://doi. org/10.1111/all.14839.

22. Blumenthal KG, Freeman EE, Saff RR, Robinson LB, Wolfson AR, Foreman RK, Hashimoto D, Banerji A, Li L, Anvari S. Delayed large local reactions to $m R$ RA-1273 vaccine against SARS-CoV-2. N Engl J Med 2021;384(13):1273-7

23. Corbeddu M, Diociaiuti A, Vinci M, Santoro A, Camisa V, Zaffina S, El Hachem M. Transient cutaneous manifestations after administration of Pfizer-BioNTech COVID-19 Vaccine: an Italian single centre case series. J Eur Acad Dermatol Venereol. 2021. https://doi.org/10.1111/jdv.17268.

24. Covid C, Team R. Allergic reactions including anaphylaxis after receipt of the first dose of Pfizer-BioNTech COVID-19 vaccine-United States, December 14-23, 2020. Morb Mortal Wkly Rep. 2021;70(2):46.

25. Frank A, Radparvar S, Manasia A, Bassily-Marcus A, Kohli-Seth R. Prolonged anaphylaxis to pfizer coronavirus disease 2019 vaccine: a case report and mechanism of action. Crit Care Explor. 2021. https:// doi.org/10.1097/CCE.0000000000000397.

26. Johnston MS, Galan A, Watsky KL, Little AJ. Delayed localized hypersensitivity reactions to the moderna COVID-19 vaccine: a case series. JAMA Dermatol. 2021. https://doi.org/10.1001/jamadermatol. 2021.1214

27. Kadali RAK, Janagama R, Peruru S, Gajula V, Madathala RR, Chennaiahgari N, Malayala SV. Adverse effects of COVID-19 mRNA-1273 vaccine: a randomized, cross-sectional study on healthcare workers with detailed self-reported symptoms. J Med Virol. 2021. https://doi. org/10.1002/jmv.26996.

28. Kelso JM. Misdiagnosis of systemic allergic reactions to mRNA COVID19 vaccines. Ann Allergy Asthma Immunol. 2021. https://doi.org/10. 1016/j.anai.2021.03.024.

29. Mathioudakis AG, Ghrew M, Ustianowski A, Ahmad S, Borrow R, Papavasileiou LP, Petrakis D, Bakerly ND. Self-reported real-world safety and reactogenicity of COVID-19 vaccines: a vaccine recipient survey. Life. 2021;11(3):249.

30. McMahon DE, Amerson E, Rosenbach M, Lipoff JB, Moustafa D, Tyagi A, Desai SR, French LE, Lim HW, Thiers BH. Cutaneous reactions reported after moderna and pfizer COVID-19 vaccination: a registry-based study of 414 cases. J Am Acad Dermatol. 2021. https://doi.org/10.1016/j.jaad. 2021.03.092.

31. Mustafa SS, Ramsey A, Staicu ML. Administration of a second dose of the moderna COVID-19 vaccine after an immediate hypersensitivity reaction with the first dose: two case reports. Ann Intern Med. 2021. https://doi.org/10.7326/L21-0104.

32. Ocáriz M, Zubeldia Ortuño J. Safety of new MRNA vaccines against COVID-19 in severe allergic patients. J Investig Allergol Clin Immunol. 2021. https://doi.org/10.18176/jiaci.0683.

33. Ontario Agency for Health Protection and Promotion (Public Health Ontario). Reports of events managed as anaphylaxis following COVID19 vaccines in Ontario: December 13, 2020 to March 6, 20212021. https://www.publichealthontario.ca/-/media/documents/ncov/epi/ covid-19-anaphylaxis-epi-summary.pdf?la=en. Accessed 29 May 2021.

34. Park LHJ, Montgomery CJR, Boggs LNA. Anaphylaxis after the Covid-19 vaccine in a patient with cholinergic urticaria. Mil Med. 2021. https:// doi.org/10.1093/milmed/usab138.

35. Pitlick MM, Sitek AN, Kinate SA, Joshi AY, Park MA. Polyethylene glycol and polysorbate skin testing in the evaluation of COVID-19 vaccine reactions: early report. Ann Allergy Asthma Immunol. 2021. https://doi. org/10.1016/j.anai.2021.03.012.

36. Restivo V, Candore G, Barrale M, Caravello E, Graziano G, Onida R, Raineri M, Tiralongo S, Brusca I. Allergy to polyethilenglicole of antiSARS CoV2 vaccine recipient: a case report of young adult recipient and the management of future exposure to SARS-CoV2. Vaccines. 2021;9(5):412.

37. Riad A, Pokorná A, Attia S, Klugarová J, Koščík M, Klugar M. Prevalence of COVID-19 Vaccine Side Effects among Healthcare Workers in the Czech Republic. J Clin Med. 2021;10(7):1428.

38. Sellaturay P, Nasser S, Islam S, Gurugama P, Ewan PW. Polyethylene glycol (PEG) is a cause of anaphylaxis to the Pfizer/BioNTech mRNA COVID-19 vaccine. Clin Exp Allergy. 2021. https://doi.org/10.1111/cea. 13874.

39. Shimabukuro T. Allergic reactions including anaphylaxis after receipt of the first dose of Moderna COVID-19 vaccine-United States, December 21, 2020-January 10, 2021. Am J Transplant. 2021;21(3):1326.

40. Shimabukuro T, Nair N. Allergic reactions including anaphylaxis after receipt of the first dose of Pfizer-BioNTech COVID-19 vaccine. JAMA 2021:325(8):780-1. 
41. Vieira J, Marcelino J, Ferreira F, Farinha S, Silva R, Proença M, Tomaz E. Skin testing with Pfizer SARS-CoV-2 vaccine and PEG 2000. Asia Pac Allergy. 2021. https://doi.org/10.5415/apallergy.2021.11.e18.

42. Rüggeberg JU, Gold MS, Bayas J-M, Blum MD, Bonhoeffer J, Friedlander S, de Souza BG, Heininger U, Imoukhuede B, Khamesipour A. Anaphylaxis: case definition and guidelines for data collection, analysis, and presentation of immunization safety data. Vaccine. 2007;25(31):5675-84.

43. Sampson HA, Muñoz-Furlong A, Campbell RL, Adkinson NF Jr, Bock SA, Branum A, Brown SG, Camargo CA Jr, Cydulka R, Galli SJ. Second symposium on the definition and management of anaphylaxis: summary report-Second National Institute of Allergy and Infectious Disease/Food Allergy and Anaphylaxis Network symposium. Journal of Allergy and Clinical Immunology. 2006;117(2):391-7.

44. Castells MC, Phillips EJ. Maintaining safety with SARS-CoV-2 vaccines. N Engl J Med. 2021;384(7):643-9.

45. Somiya M, Mine S, Yasukawa K, Ikeda S. Sex differences in the incidence of anaphylaxis to LNP-mRNA COVID-19 vaccines. Vaccine. 2021. https:// doi.org/10.1016/j.vaccine.2021.04.066.

46. Rutkowski K, Mirakian R, Till S, Rutkowski R, Wagner A. Adverse reactions to COVID-19 vaccines: a practical approach. Clin Exp Allergy. 2021. https://doi.org/10.1111/cea.13880.

47. Dages KN, Pitlick MM, Joshi AY, Park MA. Risk of allergic reaction in patients with atopic disease and recent COVID-19 vaccination. Ann Allergy Asthma Immunol. 2021. https://doi.org/10.1016/j.anai.2021.04. 024.

48. Krantz MS, Bruusgaard-Mouritsen MA, Koo G, Phillips EJ, Stone CA Jr, Garvey LH. Anaphylaxis to the first dose of mRNA SARS-CoV-2 vaccines: don't give up on the second dose. Allergy. 2021. https://doi.org/10.1111/ all.14958.

49. Vander Leek TK, Chan ES, Connors L, Derfalvi B, Ellis AK, Upton JE, Abrams EM. COVID-19 vaccine testing \& administration guidance for allergists/ immunologists from the Canadian Society of Allergy and Clinical Immunology (CSACI). Allergy Asthma Clin Immunol. 2021;17(1):1-6.

50. Panesar SS, Nwaru BI, Hickstein L, Rader T, Hamadah H, Ali DFI, Patel B, Muraro A, Roberts G, Worm M. The epidemiology of anaphylaxis in Europe: protocol for a systematic review. Clin Transl Allergy. 2013;3(1):1-5.

51. Canadian Society of Allergy and Clinical Immunology (CSACI). SARS-CoV-2 vaccine testing \& administration guidance for allergists/ immunologists from the CSACI 2021. https://csaci.ca/wp-content/uploa ds/2021/04/2021-04-10-UPDATE-COVID-19-Vaccine-Testing-Administra tion-Guidance.pdf. Accessed 26 Sep 2021.

52. Gold MS, MacDonald NE, McMurtry CM, Balakrishnan MR, Heininger U, Menning L, Benes O, Pless R, Zuber PL. Immunization stress-related response-redefining immunization anxiety-related reaction as an adverse event following immunization. Vaccine. 2020;38(14):3015-20.

53. Altrichter S, Salow J, Ardelean E, Church MK, Werner A, Maurer M. Development of a standardized pulse-controlled ergometry test for diagnosing and investigating cholinergic urticaria. J Dermatol Sci. 2014;75(2):88-93.

\section{Publisher's Note}

Springer Nature remains neutral with regard to jurisdictional claims in published maps and institutional affiliations.
Ready to submit your research? Choose BMC and benefit from:

- fast, convenient online submission

- thorough peer review by experienced researchers in your field

- rapid publication on acceptance

- support for research data, including large and complex data types

- gold Open Access which fosters wider collaboration and increased citations

- maximum visibility for your research: over $100 \mathrm{M}$ website views per year

At BMC, research is always in progress.

Learn more biomedcentral.com/submissions 